\title{
THE MECHANISM OF PHAGOCYTOSIS FROM THE ADSORPTION POINT OF VIEW.
}

\author{
By J. C. G. LEDINGHAM. \\ (Lister Institute, London.)
}

With 22 charts.

\section{INTRODUCTION.}

DURING recent years many attempts have been made to show that the interactions of antigen and antibody may in large measure be explained on a basis of physical adsorption. The immunity processes which have been most studied from this point of view have been the toxin-antitoxin reaction, the adsorption of agglutinin by bacteria and the lysis of red blood corpuscles by specific sera and lytic substances of colloidal nature.

To discuss present opinion with regard to the nature of these reactions, would be out of place here, as in this communication I shall be concerned mainly with those processes which culminate in the phagocytosis of bacteria by the polymorphonuclear leucocytes.

There is a growing opinion, not yet perhaps resting on any extensive experimental evidence, that not only the sensitisation of an organism by a specific serum, but also, possibly, the mechanism by which the sensitised organism penetrates the limiting layer of the leucocyte wall, are essentially interactions between membranes of colloidal constitution and consequently amenable to the laws of colloidal chemistry.

Before an organism can reach the interior of the phagocyte, it must have passed through at least three preparatory phases:

(1) In the first place the organism must be efficiently sensitised by the opsonin in the serum (normal or specific). The removal of opsonin from a specific serum has not so far been studied by quantitative methods with a view to determining the numerical relations 
subsisting between the opsonin adsorbed and the opsonin free after equilibrium has been attained. The removal of agglutinin by bacteria has been investigated from this standpoint by several observers (Eisenberg and Volk, Arrhenius, Bilz, Craw, Dreyer and Douglas, \&c.), and although complete agreement has not yet been reached, it would appear at least that the balance of evidence supports the view that the reaction is more accurately explained on a basis of physical adsorption than on the more physico-chemical conception set forth by Arrhenius who applied to it the partition law in a modified form. In this communication some experiments will be detailed, the results of which go to show that the quantitative relations in the case of the removal of opsonin by bacteria are most accurately satisfied by equations of the adsorption type $\frac{y}{a}=k x^{n}$ (where $y$ is the amount adsorbed, $x$ the amount free in equilibrium and $k, n$ and $a$ are constants).

The question of so-called spontaneous phagocytosis without the intervention of a normal or specific serum, though of very great interest, is not considered here, but the fact that such spontaneous phagocytosis is influenced by the salt content of the menstruum suggests that in the process of opsonisation by serum, alterations in the electrical charge on the bacterial membrane may be an essential factor. We know from the work of Bechhold, Buxton and Teague and others that the so-called agglutinin-bacteria which have been exposed to an agglutinating serum and later freed therefrom by dialysis are more readily susceptible to precipitation by electrolytes than bacteria not so treated. In the case of opsonisation the "opsonin-bacteria" enter the second phase which doubtless corresponds to the second phase of agglutination, viz., the aggregation of the agglutinin-bacteria.

(2) In the second phase the sensitised organisms congregate at the periphery of the leucocyte. The writer (Ledingham 1906) in the course of experiments on the influence of temperature on phagocytosis, observed this attachment of sensitised bacteria to the leucocytes. At low temperatures where little or no phagocytosis occurred, this ring-distribution of the sensitised bacteria was most clearly seen. The suggestion was then made that once this phase of attachment had occurred, surface tension alterations between the bacterial- and leucocyte-membranes became the determining factors in phagocytosis. It has since been shown by Levaditi and Mutermilch (1910) that a similar aggregation of trypanosomes (Nagana) takes place in the neighbourhood of the leucocytes in the presence of a specific trypanolytic serum. When 
phagocytic activity is paralysed by cold, this phase of aggregation or attachment nevertheless occurs. In the opinion of these authors, the attachment phase is to be regarded as a physico-chemical phenomenon analogous to agglutination. That a leucocyte is attracted by a sensitised trypanosome and goes out to look for it is in their opinion improbable. They regard it as far more likely that the actual attachment of the sensitised organism to the leucocyte results from a purely fortuitous rencontre of organism and phagocyte. With this opinion the writer agrees. The authors rightly point out however, that in the phenomenon of attachment there is a certain element of specificity involved. Thus (1) only sensibilised trypanosomes become attached, and (2) the attachment is only to cells of the leucocyte group and not to tissue cells such as hepatic or renal cells. The fact that only sensitised organisms become attached to leucocytes does not appear to the writer to require explanation on a specific basis. In the discussion of the first phase of sensitisation, I have pointed out that the opsonin-bacteria, like the agglutinin-bacteria, are probably in a more precipitable condition than non-sensitised bacteria. They are, in fact, as I have frequently observed, in a condition of extremely fine aggregation and if the sensitising fluid has marked agglutinating powers, the sensitised organisms are frankly clumped. That, under these conditions, therefore, sensitised organisms should be more readily cleared from the field by leucocytes than nonsensitised organisms is quite explicable on purely physical grounds. The leucocyte-membranes, with their well-known adhesive properties, clear the field probably much in the same way as coagulated egg white clarifies a turbid broth.

The fact that only cells of the leucocyte group play a part in the attachment phase, is difficult to account for on purely physical grounds. The explanation may however be found in the assumption that great variations occur in the constitution of the limiting membranes or adsorptive surfaces of cells. Under certain circumstances for example, it is known that fixed tissue cells such as hepatic cells or nerve cells may submit to penetration by foreign objects and on the other hand even among cells of the leucocytic group we know that the eosinophile cell does not, to any appreciable extent, act as a phagocyte of sensitised micro-organisms. Also among the frankly phagocytic cells such as the polymorphonuclear leucocytes, there is evidence that one cannot postulate a uniform physiological constitution of their adsorptive surfaces. We know, for example, that the immature polynuclear cells in Leukaemia have little phagocytic power probably in virtue of an incompletely 
developed adsorptive surface (Ledingham, Bushnell, \&c.), and as we shall see later, differences in the constitution of the limiting layers of amoebae have been held to afford an explanation of the differences they exbibit in the mode of ingestion of foreign particles (Rhumbler). This phase of attachment has also been studied recently by Barikine (1911) working with leucocytes and sensibilised red cells. This observer who attacked the problem experimentally, made use of an interesting phenomenon (previously studied by Ponder in this country), viz., the adhesion of polymorphonuclear cells to glass plates. The strength of this adhesion, he attempted to measure by the amount of a jet of saline of fixed volume and height, necessary to effect their detachment from the plates. Only sensibilised red cells became in turn attached to these leucocytes adhering to the glass plates and very considerable jets of saline were required to wash off these red cells once they had secured an attachment to the leucocytes. When the leucocytes had been previously heated, they did not adhere to glass plates nor did sensibilised red cells attach themselves to such damaged leucocytes.

In the experiments of Levaditi and Mutermilch, heated leucocytes did become attached to sensibilised trypanosomes. I have myself observed in certain unpublished experiments with heated leucocytes and staphylococci, that the phase of attachment nevertheless took place. Barikine suggested that the heat employed had altered the consistence of the limiting membrane of the leucocyte.

(3) I come now to the third phase, viz., the mechanism of inclusion or incorporation within the body of the phagocyte.

The actual phagocytic act has long been regarded as essentially a vital phenomenon in which the amoeboid activity of the leucocyte plays an important part, but in recent years evidence has accumulated showing that as a factor in phagocytosis amoeboid activity has been greatly overrated. In the paper quoted above, the writer carried out certain experiments the results of which suggested that, provided the leucocyte was supplied with sensitised organisms, very little difference took place in the phagocytic intake whether the incubation was carried out at $18^{\circ} \mathrm{C}$. or at $37^{\circ} \mathrm{C}$. In some as yet unpublished experiments by Priestley in this Institute it has appeared that leucocytes supplied with sensitised organisms and kept at very low temperatures may, if given sufficient time, take up a progressively increasing number of organisms. The suggestion, therefore, is that at low temperatures the velocity of reaction (velocity of intake) may undoubtedly be slower than at $37^{\circ} \mathrm{C}$. but the ultimate intake when sufficient time for equilibrium has been giveu, 
may approximate to that at $37^{\circ} \mathrm{C}$. This accords with what we know of physical adsorption, e.g., in the adsorption of dyes by filter paper.

Again it would seem that the phenomenon of amoeboid activity has received undue consideration from the manner in which it has been studied. In the course of a discussion of the rôle played by amoeboid activity in the life of the leucocyte, by Ullmann (1911), the fact is pointed out that the free-swimming polynuclear leucocyte is a perfectly round drop-like body and that it spreads itself out only in response to the stimulus caused by touching ground, e.g., on the glass slide. Moreover, the protrusion of pseudopodia occurs in response only to abnormal stimuli and the wandering leucocyte may traverse large areas and thick layers of red blood corpuscles without sending out a single pseudopodium. That amoeboid activity as such is not essential to the phagocytic act is proved by the fact that in the performance of experiments in which mixtures of serum, leucocytes and micro-organisms are incubated together, very vigorous shaking can be employed without affecting the phagocytic activity of the leucocyte. In all experiments recorded in this communication the tubes containing the various mixtures were placed in a to-and-fro shaker working vigorously in an incubator kept at $37^{\circ} \mathrm{C}$. Under these conditions it is difficult to suppose that independent leucocytic movements played any part at all in the process of phagocytosis.

The actual mechanism of entrance of red blood corpuscles into leucocytes has been studied microscopically by various observers and it would appear that most usually the impression obtained is that the leucocytic wall rises up leaving a meniscus in which the impinging red cell rests. Gradually the enveloping walls again coalesce and the red cell is imprisoned. A similar process of feeding takes place in the case of certain amoebae (Nahrungsaufnahme durch Umfliessung) (Rhumbler 1910). In amoebae also, food particles may be taken in, without any apparent movement on the part of the outer wall of the cell. The foreign body after contact with the cell wall appears. to insinuate itself into the body of the phagocyte without any movements on the part of the latter (Nahrungsaufnahme durch "Import"). In these two types of inclusion Rhumbler considers that the determining factor is a diminution in the surface tension at the point of contact of the wall of the phagocyte with the foreign body. In other amoebae with denser and more skin-like ectoplasm, the more complicated processes of circumvallation and invagination were observed, but all these variations in the method of ingestion could readily be explained on mechanical principles. 


\section{Object of the present experiments.}

The phagocytosis by leucocytes of minute objects such as bacilli cannot readily be followed microscopically but it seemed that some light might be thrown on the mechanism by investigating the quantitative relationships of the bacilli included in the leucocytes and the bacilli left free in the surrounding fluid. The present communication contains experimental data on this subject together with similar data regarding the first phase in phagocytosis, viz., the sensitisation of the organism.

For experiments of this nature, it is of great advantage to have a sensitising fluid which gives consistent results over a long series of experiments. Such a fluid was obtained by accident in the course of another research in which various guinea-pig end-pieces were being investigated. From an apparently normal guinea-pig an end-piece was prepared by the $\mathrm{CO}_{2}$ method ${ }^{1}$, which was found to give an exceedingly high phagocytic index with $B$. typhosus. The height of the phagocytic index with this fluid as compared with other end-pieces and normal complement was such as to render it extremely useful in experiments demanding long ranges of phagocytic indices. The properties of this end-piece, particularly its behaviour on dilution and on inactivation, will be first briefly recorded. Throughout the period of six months during which the experiments proceeded this end-piece was kept in the cold room at $1^{\circ}-2^{\circ} \mathrm{C}$. and samples were taken from it as required.

\section{Remarks on the effect of dilution and of inactivation by heat.}

It has to be remembered that the pure end-piece corresponds to a dilution of 1 in 10 of the original guinea-pig serum from which it was derived. No appreciable phagocytic index was obtained when the end-piece was diluted lower than 1 in 8 (i.e., 1 in 80 of original serum), and in this respect the end-piece behaved like an ordinary normal serum, in which a measurable opsonising effect usually ceases in dilutions considerably under 1 in 100 .

The fall in the phagocytic index following dilution of the end-piece was, as all the charts show, extremely regular, and, throughout the greater part of the dilution range, the points corresponding to the indices lie practically on straight lines the inclinations of which to the axis $x$

\footnotetext{
1 The exact details of the method of preparation of the end-piece from normal guineapig serum will be found in a paper by Ledingham and Dean, this Journal, Vol. xI. No. 2. 1912.
} 
vary only very slightly. To this regular behaviour of the end-piece on titration is doubtless to be attributed much of the consistency obtained by its use in the experiments recorded in this communication. That its opsonising value ceased at such a low dilution as 1 in 8 was really no disadvantage. Ranges of sufficient length could readily be obtained by shorter spacing.

In its reaction to heat, the end-piece behaved quite differently from a normal serum. Heating for 30 minutes at $55^{\circ}$ C. caused only a very

Influence of dilution on the sensitising fluid used in the experiments (end-piece).

Experiment I. (14. x. 11.)

Scheme : 3 vols. Serum +2 vols. Leucocytes +1 vol. Bacillary emulsion. Strength of Bacillary emulsion 780,000 per cub. $\mathrm{mm}$. Incubation : 14 mins. at $37^{\circ} \mathrm{C}$. in shaker.

Result: (see Chart I, A).

\begin{tabular}{|c|c|}
\hline Dilution & Bacilli per leucocyt \\
\hline 1 in 1 & $20 \cdot 01=\frac{1101}{55}$ \\
\hline 1 in 2 & $6 \cdot 62=\frac{709}{107}$ \\
\hline 1 in 4 & $0.40=\frac{49}{121}$ \\
\hline 1 in 8 & $0.02=\frac{2}{86}$ \\
\hline 1 in 16 & $0.0=\frac{0}{74}$ \\
\hline
\end{tabular}

Experiment II. (16. x. 11.)

Similar experiment to I. The end-piece was also heated $\left(30\right.$ mins. at $55^{\circ} \mathrm{C}$.) and then diluted like the unheated end-piece.

Incubation 12 mins.

Strength of emulsion $1,400,000$ per cub. mm.

Result: (see Chart I, $B$ and $C$ ).

\begin{tabular}{|c|c|c|}
\hline Dilution & $\begin{array}{l}\text { Unheated End-piece } \\
\text { Phagocytic Index }\end{array}$ & $\begin{array}{l}\text { Heated End-piece } \\
\text { Phagocytic Index }\end{array}$ \\
\hline 1 in 1 & $15 \cdot 4=\frac{1203}{78}$ & $13 \cdot 7=\frac{1440}{105}$ \\
\hline 1 in 2 & $2 \cdot 25=\frac{459}{204}$ & $0.65=\frac{161}{248}$ \\
\hline 1 in 4 & $0.097=\frac{27}{277}$ & $0.043=\frac{16}{368}$ \\
\hline 1 in 8 & $0.01=\frac{4}{234}$ & $0.01=\frac{2}{179}$ \\
\hline
\end{tabular}


slight fall in the opsonising value (Exp. II) and even 30 minutes heating at $60^{\circ} \mathrm{C}$. had the effect only of bringing the phagocytic index down to a little less than half that of the unheated end-piece. Heating at $65^{\circ} \mathrm{C}$. for 30 minutes still left a very small residuum but after heating at $70^{\circ} \mathrm{C}$.

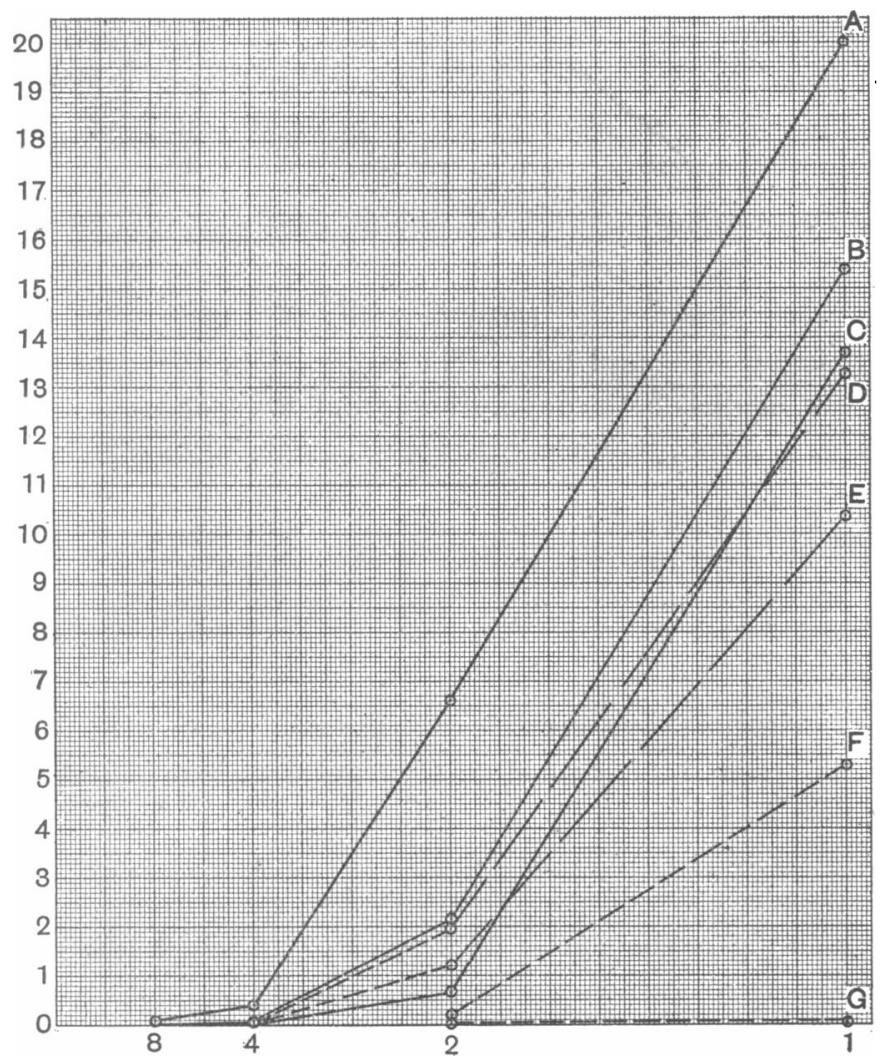

Chart I.

Experiment III. (18. x. 11.)

The end-piece was on this occasion heated at various temperatures for $\mathbf{3 0}$ mins. Dilutions were then made.

Result: (see Chart I, $D, E, F, G$ ).

$\begin{array}{cccccc}\text { Dilution } & \begin{array}{c}\text { Unheated E. } \\ \text { Phag. Index }\end{array} & \begin{array}{c}\text { E. 55 } 5^{\circ} \text { C. } \\ \text { Phag. Index }\end{array} & \begin{array}{c}\text { E. } 60^{\circ} \text { C. } \\ \text { Phag. Index }\end{array} & \begin{array}{c}\text { E. } 65^{\circ} \text { C. } \\ \text { Phag. Index }\end{array} & \begin{array}{c}\text { E. } 70^{\circ} \text { C. } \\ \text { Phag. Index }\end{array} \\ 1 \text { in } 1 & 13.27 & 10.38 & 5.32 & 0.054 & 0.018 \\ 1 \text { in } 2 & 1.98 & 1.21 & 0.4 & 0.021 & 0.00 \\ 1 \text { in } 4 & 0.19 & 0.09 & 0.025 & 0.01 & 0.00 \\ & & & & & 22-2\end{array}$


practically no phagocytic values could be obtained(Exp. III). This particular end-piece, therefore, in so far as its opsonin-content was concerned, was remarkably thermostable and might well have been derived from an ordinary immune serum.

On the specificity of the end-piece employed in the experiments.

An attempt was made to determine whether the end-piece behaved, in an adsorption process, like an immune typhoid serum.

The following mixtures were prepared :

3 vols E. +1 vol. Saline +1 vol. of thin emulsion of $B$. typhosus,

" " " " " Staph. aureus.

These were digested at room temperature for ten minutes and then centrifugalised completely. The supernatants were tested in the ordinary way, against both Staph. aureus and B. typhosus.

3 vols. E. +2 vols. Saline constituted the control unadsorbed fluid.

Result :

$\begin{array}{cc}\text { S. aureus } & \text { B. typhosus } \\ \text { Phag. Index } & \text { Phag. Index } \\ 0.03 & 7.5 \\ 0.00 & 0.05 \\ 0.00 & 6.1\end{array}$

Control unadsorbed

Supernatant after adsorption with $B$. typhosus

Supernatant after adsorption with Staph.aureus

0.00

The experiment shows very clearly that adsorption with $B$. typhosus
moves the typhoid antigen almost entirely, whereas adsorption with removes the typhoid antigen almost entirely, whereas adsorption with
Staph. aureus has practically no influence on the specific typhoidopsonins.

As I have already indicated, this end-piece came from a presumably normal guinea-pig in the course of a research in which numerous endpieces from normal guinea-pigs were examined (Ledingham and Dean

\section{Experiment IV. (25. xI. 11.)}

Scheme: 2 vols. E. +1 vol. Leucocytes +1 vol. Bacillary emulsion.

Shorter spacing employed in preparing the dilutions of the end-piece.

Result : Incubation 14 mins.

$\begin{array}{cc}\text { Dilution } & \text { Phagocytic Index } \\ 10 \text { in } 12 & 15 \cdot 14 \\ 9 \text { in } 12 & 12 \cdot 91 \\ 8 \text { in } 12 & 10 \cdot 77 \\ 7 \text { in } 12 & 8 \cdot 78 \\ 6 \text { in } 12 & 6 \cdot 05 \\ 5 \text { in } 12 & 5 \cdot 65\end{array}$


1912). Investigation of its properties might lead one to suppose that the animal from which it was derived had been in some way specifically immunised and that it had gained entrance to the normal stock by

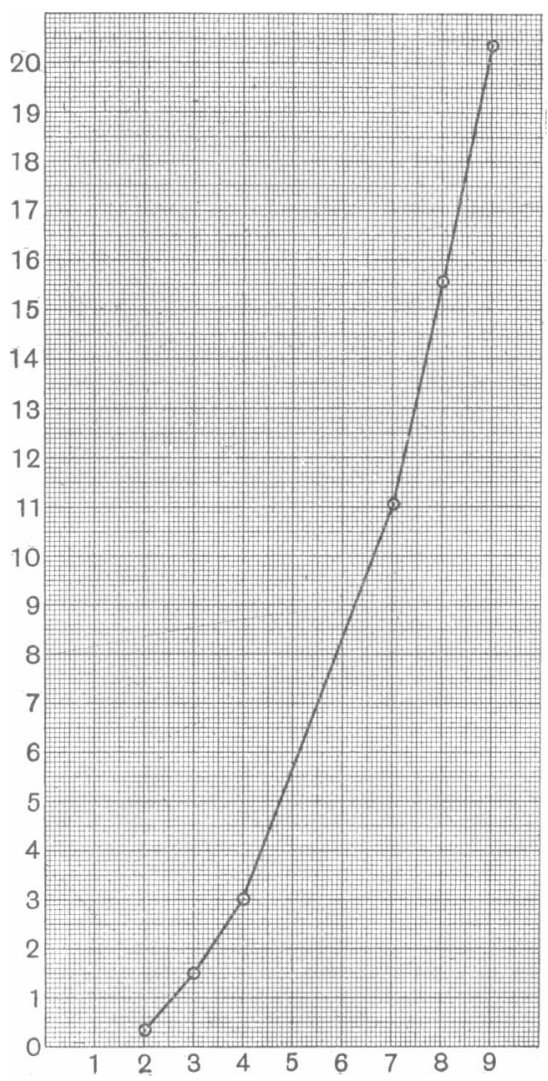

Chart II. $x$. Concentration of end-piece. y. Phagocytic index.

$$
\text { Experiment V. (18. xII. 11.) }
$$

Similar experiment to IV. Dilutions carried a little further. Result: (see Chart II).

$\begin{array}{lc}\text { Dilution } & \text { Phagocytic Index } \\ 9 \text { in } 12 & 20.35 \\ 8 \text { in } 12 & 15.55 \\ 7 \text { in } 12 & 11.06 \\ 4 \text { in } 12 & 3.02 \\ 3 \text { in } 12 & 1.51 \\ 2 \text { in } 12 & 0.35\end{array}$


mistake. This is unlikely, but if so, the only immunisation it could have received, was a sub-lethal dose of typhoid bacilli not less than six months previously. The matter must remain at present unsettled.

I now pass to the main purpose of the experiments, viz., the determination of the numerical relationships subsisting between the adsorbed (i.e., the phagocytosed) and the free (i.e., not phagocytosed) bacilli in opsonic experiments. The subject was treated in three stages as follows :

Stage I. Experiments designed to show the relation between the adsorbed and the free bacilli, where the two processes of sensitisation and phagocytosis were allowed to go on simultaneously.

Stage II. Experiments on the nature of opsonic sensitisation from the adsorption point of view.

Stage III. Experiments on the nature of the union between the leucocyte and the sensitised bacilli suspended in salt solution.

\section{Stage I. (Exps. A, B and C.) Technique of experiments.}

A moderately thick emulsion of $B$. typhosus grown on agar for about 24 hours at $25^{\circ} \mathrm{C}$. was taken and successive dilutions prepared therefrom. The number of bacilli in a convenient dilution was estimated directly with a Thoma-Zeiss apparatus. The number of leucocytes per cubic millimetre in the human blood-leucocyte emulsion was estimated by the same method. With these data, it was easy to calculate the initial ratios of bacilli to leucocytes in each cubic $\mathrm{mm}$. of the incubated fluids. This ratio (denoted $\mathrm{B} / \mathrm{L}$ in all experiments quoted) expresses simply the number of bacilli available for each leucocyte at the commencement of incubation.

The incubated fluid generally consisted of 1 vol. End-piece, 1 vol. Bacillary emulsion and 1 vol. Leucocyte emulsion (human). These were drawn up into a large-bored capillary pipette with rubber teat from which they were immediately ejected into a small test-tube and there thoroughly mixed by aid of the pipette. The tube was then placed in the to-and-fro shaker working in the incubator at $37^{\circ} \mathrm{C}$.

At the end of the period of incubation the test-tubes were withdrawn from the shaker in the order in which they went in. By means of a capillary pipette a small sample from each test-tube was immediately placed on a slide and a film prepared. This was fixed by methyl alcohol and stained by Giemsa's solution. 


\section{Experiment A. (9. xI. 11.)}

Strength of bacillary emulsion $=11,212,800$ per cub. mm. (calculated from a convenient dilution).

Strength of leucocyte emulsion $=6,180$ polymorphonuclear leucocytes per cub. $\mathrm{mm}$.

Result :

\begin{tabular}{|c|c|c|c|}
\hline $\mathrm{B} / \mathrm{L}$ & $\begin{array}{l}\text { P. I. } \\
\text { ("Amount Adsorbed") }\end{array}$ & $\begin{array}{l}\text { Percentage } \\
\text { "Adsorbed" }\end{array}$ & $\begin{array}{l}\text { Percentage } \\
\text { "Free" }\end{array}$ \\
\hline $1814 \cdot 36$ & $?$ & $?$ & $?$ \\
\hline $907 \cdot 18$ & $1.96=\frac{401}{204}$ & $0 \cdot 21$ & $99 \cdot 79$ \\
\hline $453 \cdot 59$ & $2 \cdot 18=\frac{445}{204}$ & $0 \cdot 48$ & $99 \cdot 52$ \\
\hline $226 \cdot 79$ & $3 \cdot 28=\frac{670}{204}$ & $1 \cdot 44$ & $98 \cdot 56$ \\
\hline $113 \cdot 39$ & $9 \cdot 25=\frac{1887}{204}$ & $8 \cdot 15$ & $91 \cdot 85$ \\
\hline $56 \cdot 69$ & $13 \cdot 59=\frac{1849}{136}$ & $23 \cdot 97$ & $76 \cdot 03$ \\
\hline $28 \cdot 34$ & $15 \cdot 89=\frac{2162}{136}$ & 56.06 & 43.94 \\
\hline $14 \cdot 17$ & $8 \cdot 81=\frac{1199}{136}$ & $62 \cdot 38$ & $37 \cdot 62$ \\
\hline $7 \cdot 08$ & $6 \cdot 53=\frac{1111}{170}$ & $92 \cdot 23$ & $7 \cdot 77$ \\
\hline
\end{tabular}

Experiment B. (11. I. 12 2.)

Strength of bacillary emulsion $=11,944,000$ per cub. $\mathrm{mm}$.

Result : Incubation time 11 mins.

\begin{tabular}{|c|c|c|c|}
\hline$B / L$ & $\begin{array}{l}\text { P. I } \\
\text { ("Amount adsorbed") }\end{array}$ & $\begin{array}{l}\text { Percentage } \\
\text { "Adsorbed" }\end{array}$ & $\begin{array}{l}\text { Percentage } \\
\text { "Free" }\end{array}$ \\
\hline $1493 \cdot 0$ & $0 \cdot 11=\frac{36}{317}$ & $0 \cdot 007$ & $99 \cdot 92$ \\
\hline $746^{\circ} \cdot 5$ & $0.087=\frac{24}{275}$ & $0 \cdot 011$ & $99 \cdot 99$ \\
\hline $373 \cdot 25$ & $0 \cdot 33=\frac{66}{199}$ & 0.088 & $99 \cdot 91$ \\
\hline $186 \cdot 62$ & $1.79=\frac{426}{238}$ & 0.95 & $99 \cdot 05$ \\
\hline $93 \cdot 31$ & $5 \cdot 89=\frac{1403}{238}$ & $6 \cdot 31$ & $93 \cdot 69$ \\
\hline $46 \cdot 65$ & $9 \cdot 69=\frac{1318}{136}$ & $20 \cdot 77$ & $79 \cdot 23$ \\
\hline $23 \cdot 32$ & $7 \cdot 02=\frac{955}{136}$ & $30 \cdot 09$ & $69 \cdot 91$ \\
\hline $11 \cdot 66$ & $5 \cdot 30=\frac{721}{136}$ & $45 \cdot 45$ & $54 \cdot 55$ \\
\hline $5 \cdot 83$ & $2 \cdot 95=\frac{689}{233}$ & $50 \cdot 60$ & $49 \cdot 40$ \\
\hline
\end{tabular}


Experiment C. (5. II. 12.)

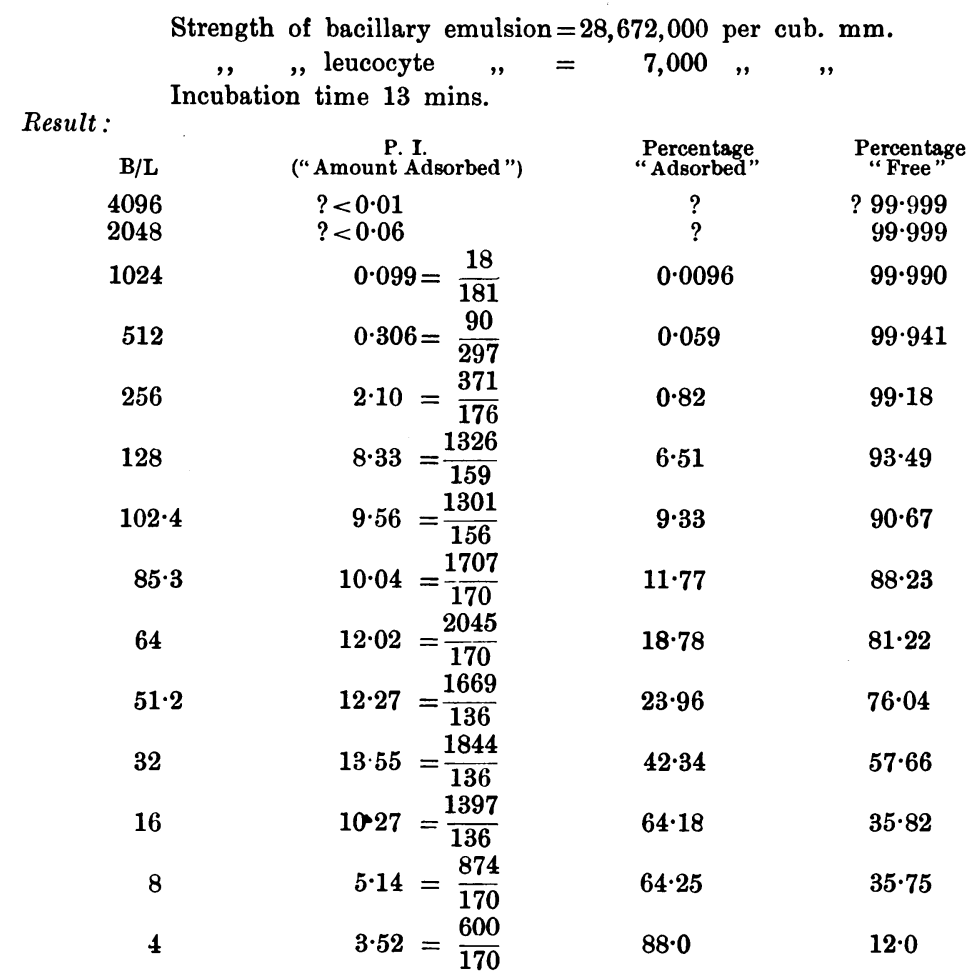

As a rule the number of leucocytes counted in each case was well over one hundred and frequently counts of 200 or 300 were made. The actual number of leucocytes counted in each experiment will be quoted. The phagocytic index so obtained gave the average number of bacilli taken up by each leucocyte (denoted in the experiment by P. I., phagocytic index, or "Amount adsorbed").

By subtraction of $P$. I. from the initial ratio $B / L$, the number of bacilli left free outside the leucocyte was calculated ("Amount free").

\section{Analysis of experiments $A, B$ and $C$.}

In each of these three experiments, the numerical results of which are quoted, there are three constants, viz., (1) the amount of sensitising fluid, (2) the number of leucocytes (i.e., the "Adsorbent"), and (3) the period of incubation, and one variable, viz., the concentration of bacilli. 
As the concentration of bacilli increases and consequently also the ratio $\mathrm{B} / \mathrm{L}$, the phagocytic index (or the amount "adsorbed" per leucocyte) increases up to a maximum. With further increase of the ratio $\mathrm{B} / \mathrm{L}$, the phagocytic index progressively falls. The course of events is, in fact, exactly analogous to what takes place when increasing quantities of antigen are added to a constant amount of a precipitating antiserum. It is possible, therefore, to choose two entirely different concentrations of bacilli (antigen) which with a constant quantity of antiserum will give similar phagocytic indices.

The fall in the index which occurs after the maximum is reached is obviously due to excess of antigen, the consequence being that the number of bacilli completely sensitised by the available antiserum continually diminishes and approaches the zero line in asymptotic fashion.

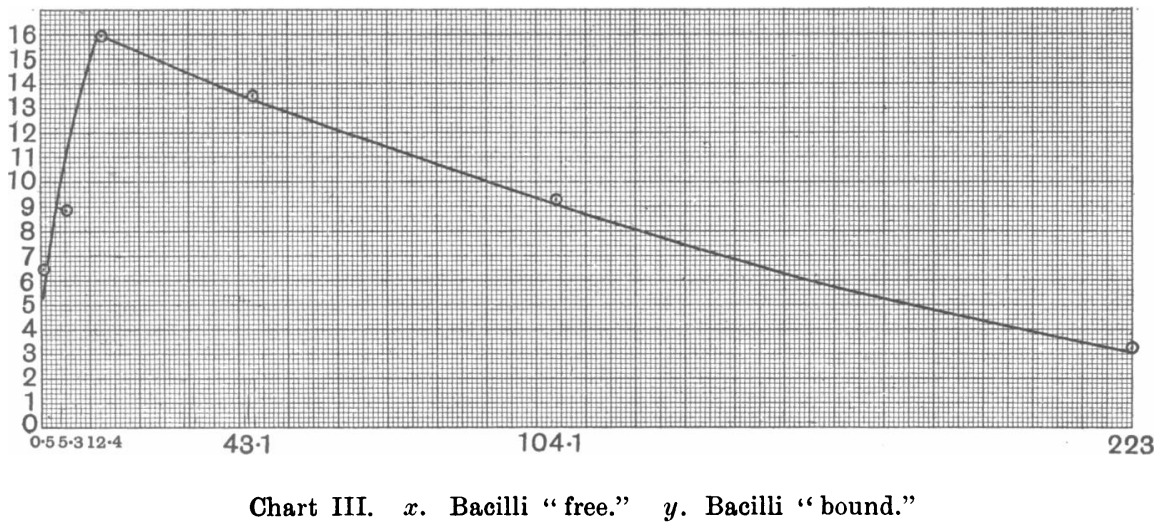

In Charts III, IV, and V are shown portions of the curves obtained by plotting the "Total amounts adsorbed" ( $=\mathrm{P}$. Indices) against the "Total amounts free" (=B/L-P. I.) in the experiments A, B, C. The curves are similar in type, each consisting of two portions-one slightly concave and the other convex to the axis of $x$.

Although, however, it is impossible to find a relationship between the "Amount adsorbed" and the "Amount free" which will hold good throughout the whole extent of these discontinuous curves, a very definite relation is found to subsist between the initial concentration of bacilli and the "Percentage amount adsorbed" (or the "Percentage amount free").

As the initial concentration of bacilli increases, the "Percentage amount free" progressively increases and approaches the value 100 


\section{4}

\section{Mechanism of Phagocytosis}

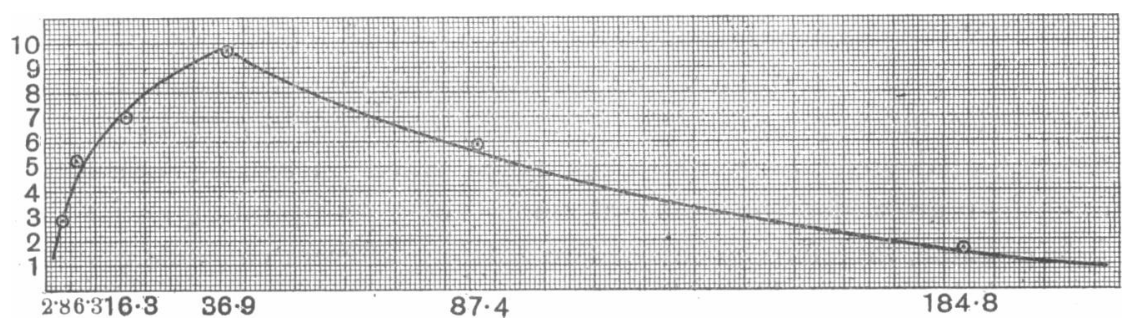

Chart IV. x. Bacilli “"free." $y$. Bacilli " bound."

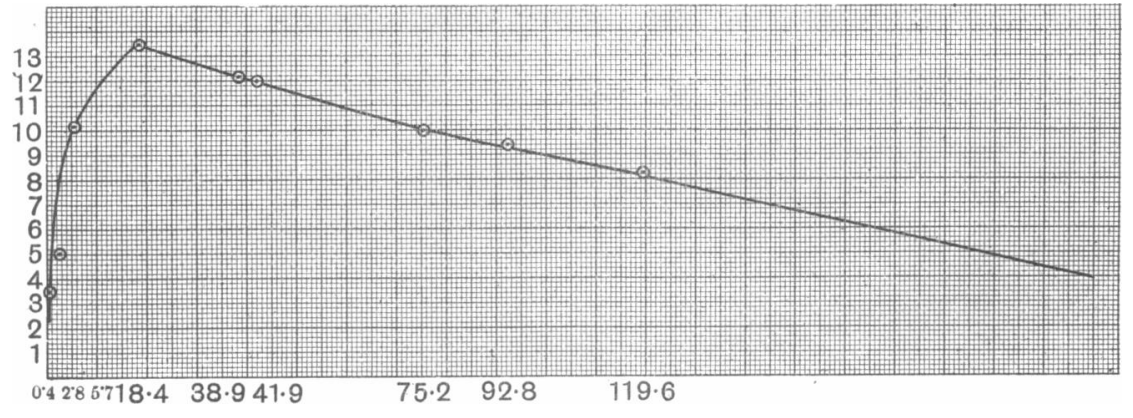

Chart V. x. Bacilli "free." y. Bacilli "bound."

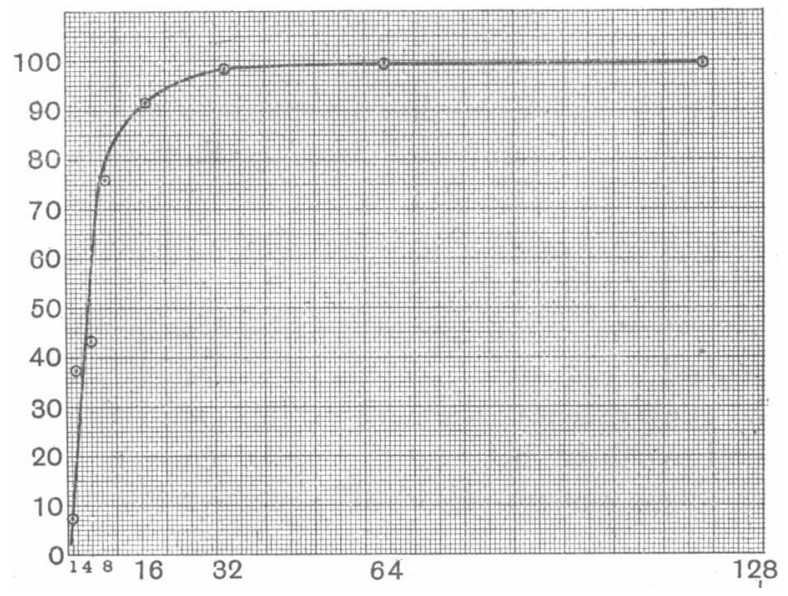

Chart VI. $x$. Initial concentration of bacilli. $y$. Percentage of bacilli "free." 
asymptotically. Or, as the initial concentration of bacilli diminishes, the "Percentage amount adsurbed" progressively increases until a point is reached at which (as in Exp. A) over $90 \%$ of the available bacilli are taken up. In Charts VI, VII, and VIII, the initial concentrations of bacilli (from Exps. A, B, and C) are plotted against the "Percentage free" and it will be seen that in all three cases, the points so obtained lie on a smooth curve to which the line $y=100$ is an asymptote.

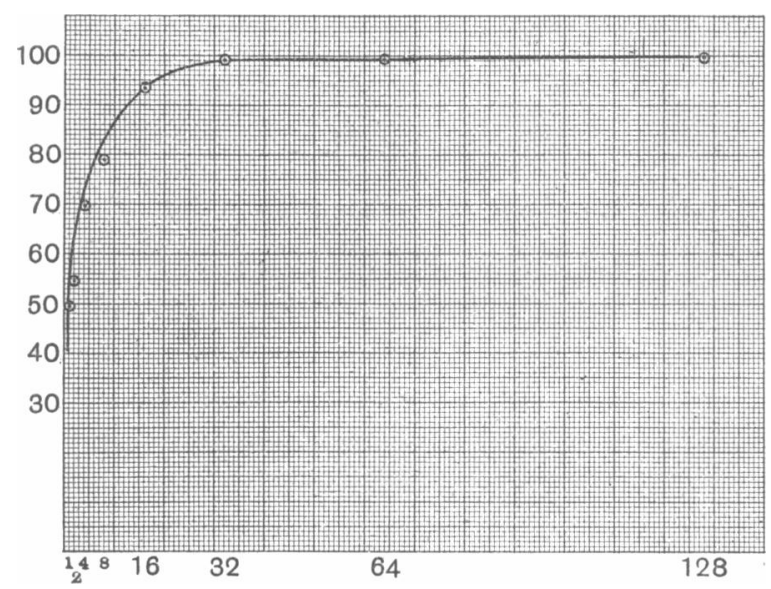

Chart VII. $x$. Initial concentration of bacilli. $y$. Percentage of bacilli " free."

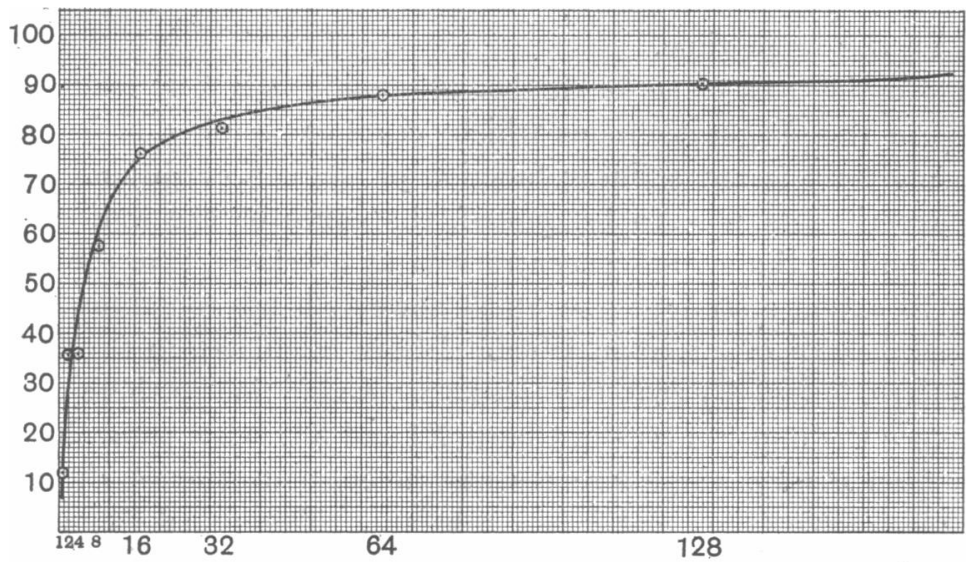

Chart VIII. $x$. Initial concentration of bacilli. $y$. Percentage of bacilli "free." 
The curves are hyperbolic in type but I have been unable to find a satisfactory mathematical expression for them. The processes involved in this type of experiment are, however, extremely complicated as the two phases of sensitisation and phagocytosis (both probably of an adsorption character) proceed simultaneously and the time is constant. The limitation of the period of incubation to 10-12 minutes is necessary in order to avoid intracellular lytic changes which would interfere with accurate enumeration.

In the following two stages the phenomena of sensitisation (opsonisation) and of phagocytosis of sensitised organisms are treated separately.

\section{Stage II.}

Opsonisation from the adsorption point of view.

The experiments bearing on this question took the following general type. A series of dilutions of the sensitising fluid (end-piece) in saline were prepared. Each of these dilutions was digested for a certain time at a certain temperature, with a constant number of bacilli. At the end of the period of digestion, the tubes were completely centrifugalised and the supernatant fluids collected. The relative amounts of opsonin left in each of these supernatants were then estimated by means of the phagocytic index, a fresh typhoid emulsion being employed for this purpose. These phagocytic indices represented the relative amounts of opsonin "free." The relative amounts of opsonin " bound" were ascertained by subtracting the phagocytic indices of the various supernatants from the indices of the corresponding undigested dilutions, all being tested at the same time.

In adopting this value for the bound opsonin it is fully realised that the fall in the phagocytic index which occurs on simple dilution of the sensitising fluid is not a linear function of the concentration. In the three experiments now to be quoted, the curve of the indices when plotted against the serum-concentrations as abscissae, is in the greater part of its extent a straight line which however bends round towards the origin as the axis of $x$ is approached. I have calculated in two of these cases (Exps. E and F) that the closest approximation to these dilution curves (see the upper curves in Charts XI and XIII) is a parabolic curve of the form $x^{2}=k y$, where $x$ represents the concentration of the serum, $y$ the phagocytic index and $k$ is a constant. The actual value of the exponent of $x$ was calculated in these two cases to be $2 \cdot 1$ and $2 \cdot 3$ which figures gave excellent values for the corresponding constants. 
The lower curves in these charts, representing the indices of the supernatants, are also of logarithmic type but the exponents of $x$ are as might be expected from their appearance much higher. In the three cases quoted the values of $n$ were $6 \cdot 1,10 \cdot 0$ and $3 \cdot 3$ respectively.

\section{Experiment D. (25. XI. 11.)}

The following digestions were carried out for 55 mins. at $37^{\circ} \mathrm{C}$. and 85 mins. at room temperature. (Total volume in each 0.6 c.c.)

1. $0 \cdot 5$ c.c. $\mathrm{E} .+0 \quad$ c.c. saline $+0 \cdot 1$ c.c. bacillary emulsion.

2. 0.45 c.c. E. +0.05 c.c. saline + do. do.

3. 0.4 c.c. $\mathrm{E} .+0 \cdot 1$ c.c. saline + do. do.

4. 0.35 c.c. E. $+0 \cdot 15$ c.c. saline + do. do.

5. $0 \cdot 30$ c.c. E. $+0 \cdot 2$ c.c. saline + do. do.

6. $0 \cdot 25$ c.c. $\mathbf{E} .+0 \cdot 25$ c.c. saline + do. do.

After centrifugalisation, the supernatants were collected and their phagocytic indices estimated. At the same time the indices of the following unadsorbed dilutions were estimated.
1. 0.5 c.c. $\mathbf{E} .+0 \cdot 1$ c.c. saline.
2. $0 \cdot 45$ c.c. $\mathrm{E} .+0 \cdot 15$ c.c. saline.
3. $0 \cdot 4$ c.c. $\mathrm{E} .+0 \cdot 2$ c.c. saline.
4. $0 \cdot 35$ c.c. E. $+0 \cdot 25$ c.c. saline.
5. $0 \cdot 3$ c.c. $\mathrm{E} .+0 \cdot 3$ c.c. saline.
6. $0 \cdot 25$ c.c. $\mathrm{E} .+0 \cdot 35$ c.c. saline.

(Total volume in each $0 \cdot 6$ c.c.)

Result :

$\begin{array}{ccccc}\begin{array}{c}\text { Concentration of } \\ \text { sensitising fluid. E. }\end{array} & \begin{array}{c}\text { P. I. before } \\ \text { adsorption }\end{array} & \begin{array}{c}\text { P. I after adsorption } \\ \text { or "Amount Free" }\end{array} & \begin{array}{c}\text { Amount } \\ \text { "Bound" }\end{array} & \begin{array}{c}\text { Percentage } \\ \text { "Bound" }\end{array} \\ 10 \text { in } 12 & 15 \cdot 141=\frac{2574}{170} & 5 \cdot 129=\frac{1108}{216} & 10 \cdot 012 & 66 \cdot 12 \\ 9 \text { in } 12 & 12 \cdot 911=\frac{1317}{102} & 3 \cdot 447=\frac{586}{170} & 9 \cdot 464 & 73 \cdot 3 \\ 8 \text { in } 12 & 10 \cdot 779=\frac{1466}{136} & 1 \cdot 352=\frac{230}{170} & 9 \cdot 427 & 87 \cdot 4 \\ 7 \text { in } 12 & 8 \cdot 784=\frac{896}{102} & 0 \cdot 7563=\frac{180}{238} & 8 \cdot 027 & 91 \cdot 3 \\ 6 \text { in } 12 & 6 \cdot 054=\frac{1120}{185} & ? 0 \cdot 2 & ? 5 \cdot 854 & ? 96 \cdot 6 \\ 5 \text { in } 12 & 5 \cdot 654=\frac{803}{142} & 0.0867=\frac{19}{219} & 5.567 & 98 \cdot 4\end{array}$

It will be seen that, as the concentration of the sensitising fluid diminishes, the percentage amount of opsonin bound progressively increases. 
In Chart IX the curves of the phagocytic indices of the supernatants and of the unadsorbed serum-dilutions, respectively, have been plotted, and in Chart X are shown the points obtained by plotting the "bound" against the "free" opsonin. On the same chart the logarithms of these latter values are plotted and it will be seen that a straight line can be made to pass very closely through them.

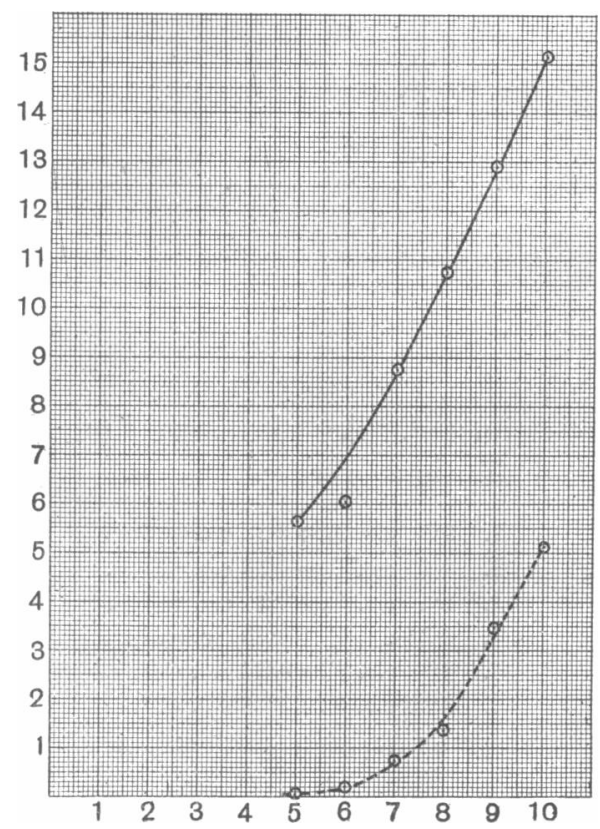

Chart IX. $x$. Initial concentration of end-piece. $y$. Phagocytic Indices. Upper curve unadsorbed. Lower curve supernatant.

Analysis. Assuming that the union of opsonin and bacilli is of the nature of an adsorption process, expressible by the equation $Y=K x^{n}$, where $Y$ represents the "amount bound," $x$ the "amount free" (in equilibrium) and $K$ and $n$ are constants, the best value of " $n$ " in the equation $\log Y=\log K+n \log x$ is deduced in the following way :

\begin{tabular}{cccc} 
Bound $(Y) \times 100$ & Free $(X) \times 100$ & Log. Bound $(y)$ & Log. Free $(x)$ \\
$1001 \cdot 2$ & $512 \cdot 9$ & $3 \cdot 005181$ & $2 \cdot 700033$ \\
$946 \cdot 4$ & $344 \cdot 7$ & $2 \cdot 976075$ & $2 \cdot 537441$ \\
$942 \cdot 7$ & $135 \cdot 2$ & $2 \cdot 974374$ & $2 \cdot 130977$ \\
$802 \cdot 77$ & $75 \cdot 63$ & $2 \cdot 904553$ & $1 \cdot 878694$ \\
$? 585 \cdot 4$ & $? 20 \cdot 00$ & $2 \cdot 767453$ & $1 \cdot 30103$ \\
$556 \cdot 73$ & $8 \cdot 67$ & $2 \cdot 745621$ & $0 \cdot 938019$ \\
\multicolumn{2}{r}{ Mean of $x=1 \cdot 914365667}$. & Mean of $y=2 \cdot 895542833$.
\end{tabular}




\section{J. C. G. Ledingham}

Deviations from means :

\begin{tabular}{|c|c|c|c|}
\hline$x^{1}$ & $y^{1}$ & $x^{1} y^{1}$ & $\left(x^{1}\right)^{2}$ \\
\hline$+\cdot 7856673$ & $+\cdot 10963817$ & $+\cdot 086139$ & $\cdot 6172731$ \\
\hline$+\cdot 6230753$ & $+\cdot 0805322$ & $+\cdot 0501776$ & $\cdot 3882228$ \\
\hline$+\cdot 21661133$ & $+\cdot 078831167$ & $+\cdot 0170757$ & $\cdot 0469205$ \\
\hline$-\cdot 0356717$ & $+\cdot 0090102$ & $-\cdot 0003214$ & $\cdot 0012725$ \\
\hline$-\cdot 61333567$ & $-\cdot 1280898$ & $+\cdot 078562$ & $\cdot 3761806$ \\
\hline - $\cdot 97634667$ & $-\cdot 149921833$ & $+\cdot 1463757$ & .9532528 \\
\hline
\end{tabular}

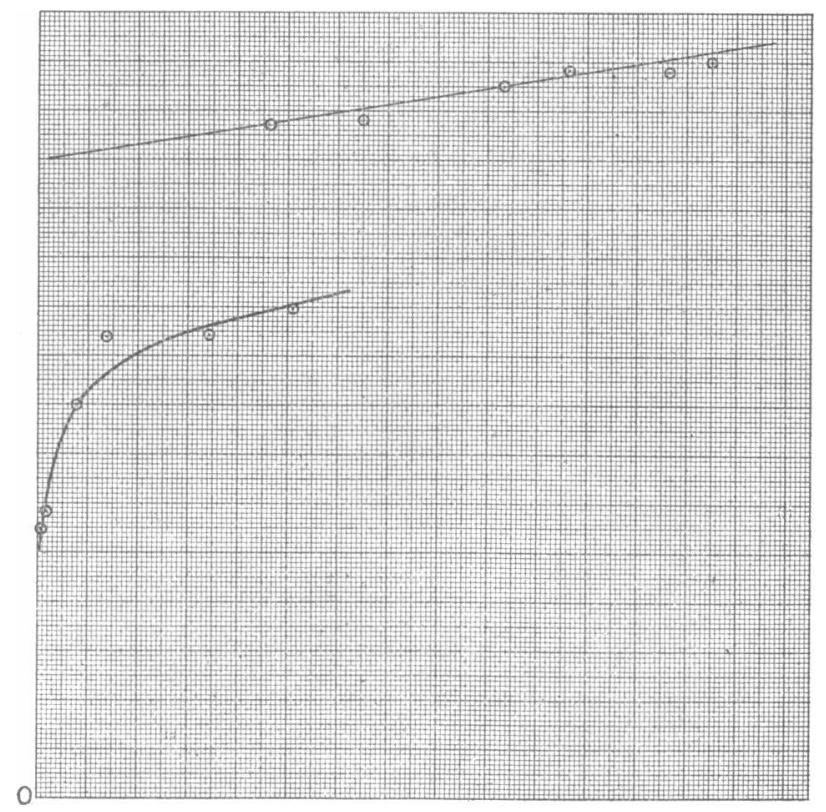

Chart X. x. Log. Opsonin “free." y. Log. Opsonin "bound." (Upper curve.) $x$. Opsonin "free." y. Opsonin "bound." (Lower curve.)

The value 0.158 for the exponent " $n$ " gives the following values for $\log K^{1}$ :

$\begin{array}{lr}2 \cdot 578 & \text { and for } K^{1} 378 \\ 2 \cdot 575 & 375 \\ 2 \cdot 637 & 433 \\ 2 \cdot 607 & 404 \\ 2 \cdot 561 & 363 \\ 2 \cdot 597 & 395\end{array}$

As the figures for the "bound" and "free" have been multiplied by 100 , the values of $\log K$ in the equation $y=k x^{n}$ are calculated from the following equation :

$\log K=\log K^{1}+2(\cdot 158)-2$. 
These values of $\log K$ are therefore (with $n=0 \cdot 158$ )

\begin{tabular}{|c|c|}
\hline $\begin{array}{l}0 \cdot 894 \\
0.891\end{array}$ & and for $K \begin{array}{r}7 \cdot 83 \\
7 \cdot 78\end{array}$ \\
\hline 0.953 & 8.97 \\
\hline 0.923 & $8 \cdot 37$ \\
\hline 0.877 & $7 \cdot 53$ \\
\hline 0.913 & $8 \cdot 18$ \\
\hline
\end{tabular}

An equation therefore of the adsorption type $Y=K x^{0.158}$ will express very satisfactorily the relation in equilibrium of the bound to the free opsonin.

\section{Experiment E. (18. xII. 11.)}

Successive dilutions of the sensitising fluid were digested as in the last experiment, with a fixed volume of bacillary emulsion.

Period of digestion 45 minutes at $37^{\circ} \mathrm{C}$.

After digestion the tubes were immediately centrifugalised. The phagocytic indices of the supernatants were then estimated and compared with those of the corresponding unadsorbed dilutions.

$$
\text { Result : }
$$

Concentration of
sensitising fluid.

\begin{tabular}{|c|c|c|c|c|}
\hline 9 in 12 & $20 \cdot 35=\frac{1791}{88}$ & $1 \cdot 69=\frac{461}{272}$ & $18 \cdot 66$ & $91 \cdot 2$ \\
\hline 8 in 12 & $15 \cdot 55=\frac{2115}{136}$ & $0.63=\frac{193}{306}$ & $14 \cdot 92$ & $95 \cdot 9$ \\
\hline 7 in 12 & $11 \cdot 06=\frac{1129}{102}$ & $0 \cdot 128=\frac{30}{233}$ & $10 \cdot 93$ & $98 \cdot 8$ \\
\hline 4 in 12 & $3 \cdot 02=\frac{417}{138}$ & $0 \cdot 0266=\frac{4}{150}$ & $2 \cdot 993$ & $99 \cdot 1$ \\
\hline 3 in 12 & $1 \cdot 51=\frac{290}{192}$ & $?$ & & \\
\hline 2 in 12 & $0 \cdot 356=\frac{99}{278}$ & $?$ & & \\
\hline
\end{tabular}

Obviously, in the above experiment, the amount of bacilli used for digestion with the serum dilutions, was too large to permit a suitable range of "free-opsonin" values capable of accurate estimation. Even in the case of the highest concentration of serum, the digestion effected a removal of over $90 \%$ of the available opsonin. In spite of the short range, however, it is quite apparent that with falling concentration of serum the relative amount of opsonin removed, increases progressively.

In Chart XI are plotted the curves formed by the indices of the supernatants and the unadsorbed fluids respectively, and in Chart XII the "opsonin bound" is plotted against the "opsonin free." The points obtained by plotting the logs. of these quantities are shown on the same chart (Chart XII). 
Analysis of Experiment $E$.

$\begin{array}{cccc}\text { Bound } \times 100 & \text { Log. Bound } & \text { Free } \times 100 & \text { Log. Free } \\ 1866 & 3 \cdot 270912 & 169 & 2 \cdot 22788 \\ 1492 & 3 \cdot 173769 & 63 & 1 \cdot 79934 \\ 1093 \cdot 2 & 3 \cdot 03862 & 12 \cdot 8 & 1 \cdot 10721 \\ 299 \cdot 34 & 2 \cdot 476107 & 2 \cdot 66 & 0 \cdot 42488\end{array}$

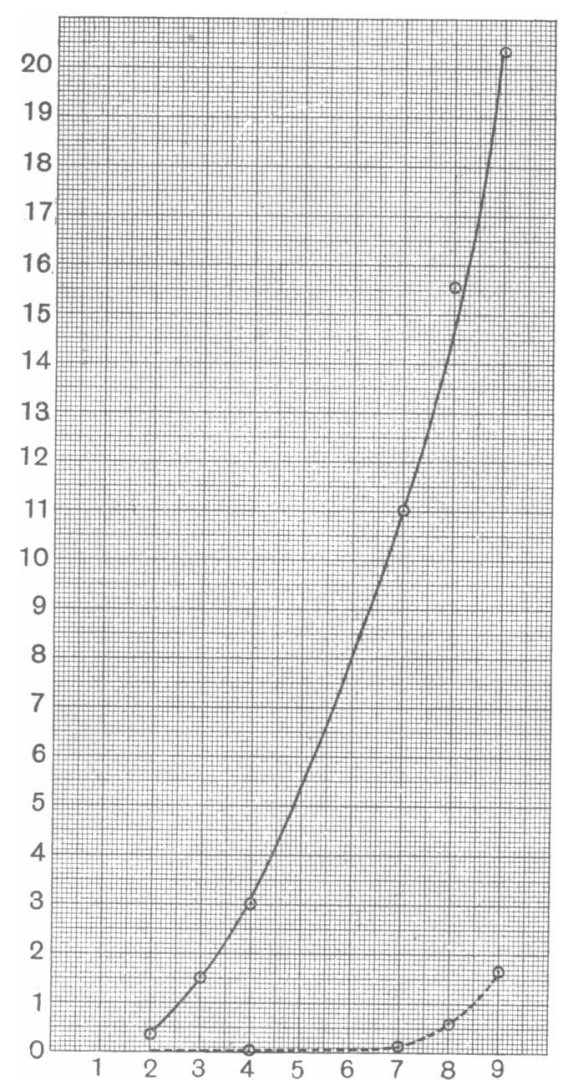

Chart XI. $x$. Initial concentration of end-piece. $y$. Phagocytic indices.

Upper curve unadsorbed. Lower curve supernatant.

The value $0 \cdot 217$ for the exponent " $n$ " gives the following values for $\log K$ :

\begin{tabular}{|c|c|}
\hline $1 \cdot 221$ & and for $K 16 \cdot 64$ \\
\hline $1 \cdot 217$ & $16 \cdot 48$ \\
\hline $1 \cdot 222$ & $16 \cdot 68$ \\
\hline 0.917 & $8 \cdot 26$ \\
\hline
\end{tabular}

Journ. of Hyg. xII 
That the fourth point is so far ont, is in all probability explained by inaccuracy in estimating the corresponding low phagocytic index.

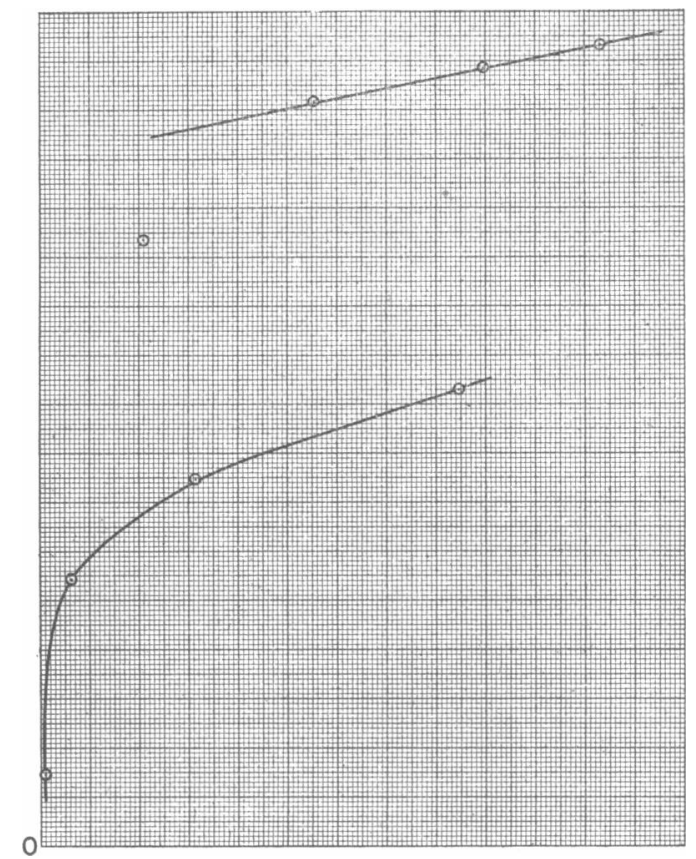

Chart XII. x. Log. Opsonin "free." $y$. Log. Opsonin " bound." (Upper curve.) $x$. Opsonin "free." y. Opsonin " bound." (Lower curve.)

\section{Experiment F. (2. I. 12.)}

On this occasion a very thin emulsion of bacilli was employed for digestion purposes. Technique in other respects similar.

\section{Result :}

$\begin{array}{cc}\begin{array}{c}\text { Concentration of } \\ \text { sensitising fluid. E. }\end{array} & \begin{array}{c}\text { P. I. before } \\ \text { adsorption }\end{array} \\ 9 \text { in } 12 & 17 \cdot 22 \\ 8 \text { in } 12 & 14 \cdot 4 \\ 7 \text { in } 12 & 11 \cdot 5 \\ 6 \text { in } 12 & 8 \cdot 67 \\ 5 \text { in } 12 & 6 \cdot 05 \\ 4 \text { in } 12 & 3 \cdot 3 \\ 3 \text { in } 12 & 1 \cdot 088 \\ 2 \text { in } 12 & 0 \cdot 76\end{array}$

P. I.after adsorption
or "Amount Free"
6.30
$4 \cdot 71$
$3 \cdot 4$
$2 \cdot 1$
$1 \cdot 1$
0.403
0.08
0.038

$\begin{array}{cc}\begin{array}{c}\text { Amount, } \\ \text { "Bound" }\end{array} & \begin{array}{c}\text { Percentage } \\ \text { "Bound" }\end{array} \\ 10 \cdot 92 & 63 \\ 9 \cdot 69 & 67 \\ 8 \cdot 1 & 70 \\ 6 \cdot 57 & 75 \\ 4 \cdot 95 & 81 \\ 2 \cdot 89 & 87 \\ 1 \cdot 008 & 92 \\ 0 \cdot 722 & 95\end{array}$


In Chart XIII are plotted the curves formed by the indices of the supernatants and the corresponding unadsorbed fluids and in Chart XIV the curve connecting the "opsonin bound" with the "opsonin free" in equilibrium has been plotted. On the same chart are also shown the points obtained by plotting the logarithms of these quantities.

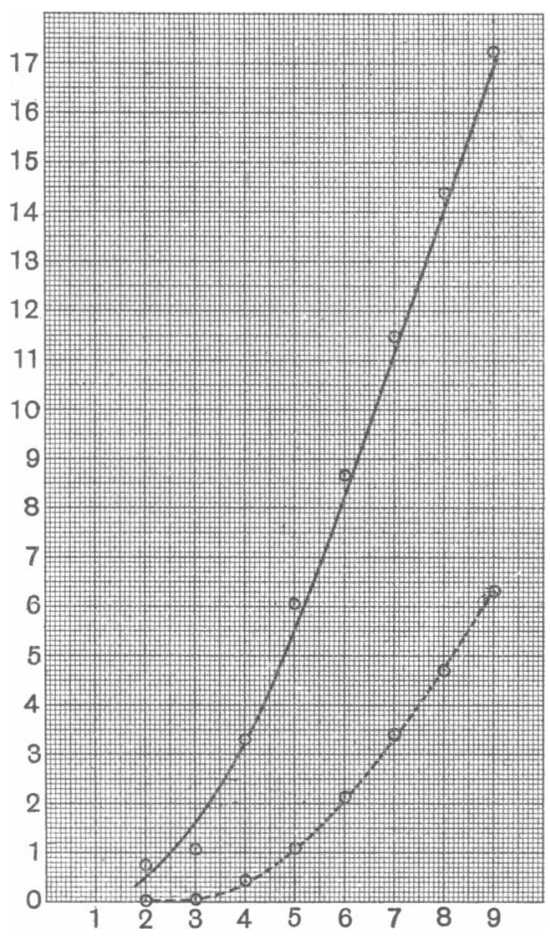

Chart XIII. $x$. Initial concentration of end-piece. $y$. Phagocytic indices. Upper curve unadsorbed. Lower curve supernatant.

$$
\text { Analysis of Experiment } F \text {. }
$$

$\begin{array}{cccc}\text { Bound } \times 100 & \text { Log. Bound } & \text { Free } \times 100 & \text { Log. Free } \\ 1092 & 3 \cdot 0382 & 630 & 2 \cdot 7993 \\ 969 & 2 \cdot 9863 & 471 & 2 \cdot 6730 \\ 810 & 2 \cdot 9084 & 340 & 2 \cdot 5314 \\ 657 & 2 \cdot 8175 & 210 & 2 \cdot 3222 \\ 495 & 2 \cdot 6946 & 110 & 2 \cdot 0413 \\ 289 \cdot 7 & 2 \cdot 4608 & 40 \cdot 3 & 1 \cdot 6053 \\ 100 \cdot 8 & 2 \cdot 003 & 8 \cdot 0 & 0 \cdot 903 \\ 6 \cdot 2 & 0 \cdot 792 & 3 \cdot 8 & 0 \cdot 5797\end{array}$


From Chart XIV it will be seen that the first six points fall almost exactly on a straight line, the 7 th and 8th points (corresponding to the very low indices) being slightly out.

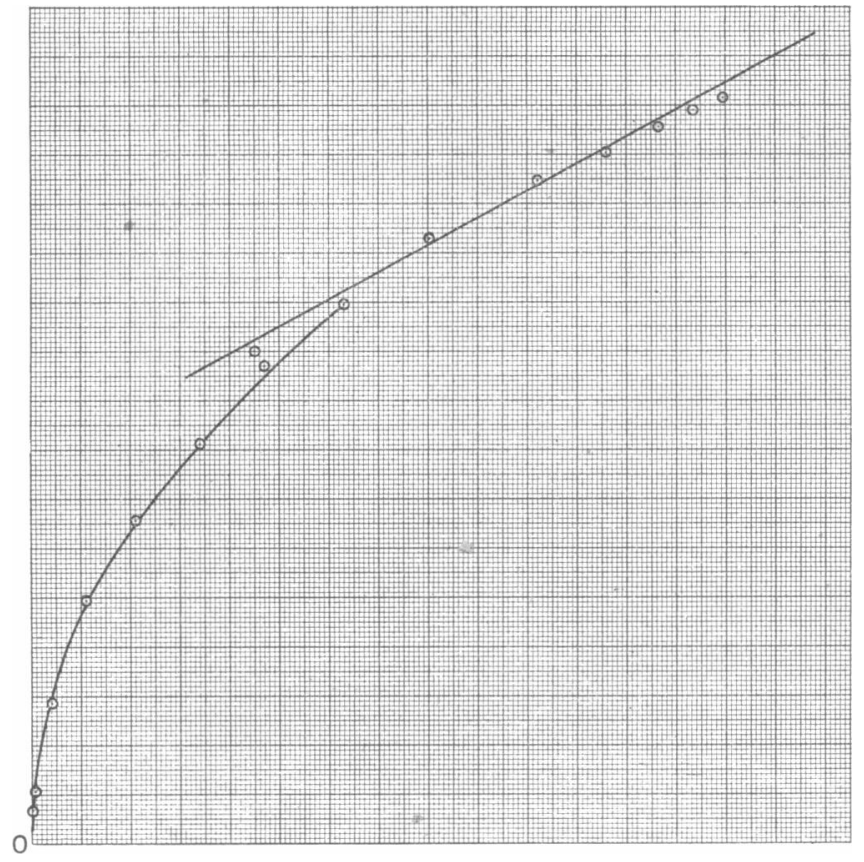

Chart XIV. $x$. Log. Opsonin "free." $y$. Log. Opsonin " bound." (Upper curve.) $x$. Opsonin "free." $y$. Opsonin " bound." (Lower curve.)

The value 0.48 for the exponent " $n$ " gives the following values for $\log K^{1}$ :

$\begin{array}{lr}1 \cdot 694 & \text { and for } K^{1} 14 \cdot 77 \\ 1 \cdot 703 & 14 \cdot 80 \\ 1 \cdot 693 & 14 \cdot 76 \\ 1 \cdot 702 & 14 \cdot 79 \\ 1 \cdot 714 & 14 \cdot 83 \\ 1 \cdot 691 & 14 \cdot 76 \\ 1 \cdot 570 & 14 \cdot 35 \\ 1 \cdot 580 & 14.39\end{array}$

The agreement between these values of $K^{1}$ (with exception of the latter two, corresponding to the low indices) is exceedingly satisfactory. 
Further experiments on adsorption of opsonin by bacilli.

Experiment $G$.

In this experiment a constant quantity of serum (end-piece) was digested with varying quantities of bacilli for a certain fixed time. The mixtures were then centrifigalised and the phagocytic indices of the supernatants tested in the ordinary way.

The original bacillary emulsion was found to contain $11,639,000$ bacilli per cub. mm. From this emulsion various dilutions were prepared.

The following mixtures were digested for $1 \frac{1}{2}$ hours at room temperature and 45 minutes at $37^{\circ} \mathrm{C}$.:

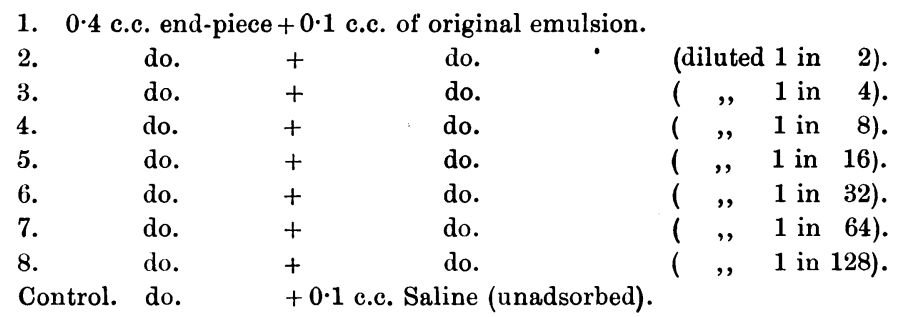

After digestion the tubes were centrifugalised and the supernatants collected. The phagocytic indices of these supernatants were then tested and compared with that of the unadsorbed end-piece.

\begin{tabular}{|c|c|c|c|c|c|}
\hline \multicolumn{4}{|l|}{ Result: } & \multirow{2}{*}{$\begin{array}{c}\begin{array}{c}\text { Phagocytic } \\
\text { Index }\end{array} \\
5 \cdot 9=\frac{806}{136}\end{array}$} & \multirow{2}{*}{$\begin{array}{c}\text { Percentage } \\
\text { "Free" } \\
100 \cdot 0\end{array}$} \\
\hline Unadsorbed serum & $\ldots$ & & $\cdots$ & & \\
\hline After adsorption with & bacillary emulsion & $(1$ in 1 & 128) & $2 \cdot 8=\frac{581}{204}$ & $47 \cdot 4$ \\
\hline do. & do. & $(1 \mathrm{in}$ & 64) & $1.5=\frac{259}{170}$ & $25 \cdot 4$ \\
\hline do. & do. & ( 1 in & 32) & $0 \cdot 81=\frac{138}{170}$ & $13 \cdot 7$ \\
\hline do. & do. & $(1$ in & 16) & $0.5=\frac{85}{170}$ & $8 \cdot 4$ \\
\hline do. & do. & $(1$ in & 8) & $0.72=\frac{104}{144}$ & $12 \cdot 2$ \\
\hline do. & do. & $(1 \mathrm{in}$ & 4) & $0 \cdot 63=\frac{93}{147}$ & $10 \cdot 6$ \\
\hline do. & do. & $(1$ in & 2) & $0 \cdot 32=\frac{67}{204}$ & $5 \cdot 4$ \\
\hline do. & do. & $(1$ in & 1) & $0 \cdot 43=\frac{89}{204}$ & $7 \cdot 2$ \\
\hline
\end{tabular}


In the annexed Chart XV the percentages of free opsonin have been plotted against the bacillary concentrations employed for adsorption. The curve so formed descends at first very rapidly towards the axis of $x$. It then proceeds very slowly and with some irregularity (points 5, 6 and 7 ) but a complete depletion of the opsonin is not attained at least within the limits of the present experiment.

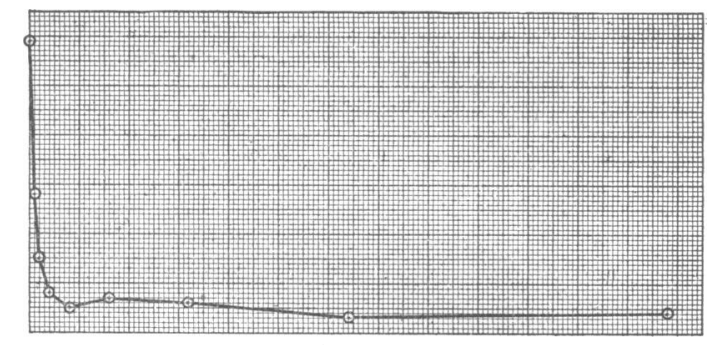

Chart XV. $x$. Concentration of bacilli used for adsorption. $y$. Phagocytic indices of supernatants.

\section{Experiment $H$.}

On the rate of adsorption of opsonin by typhoid bacilli at $37^{\circ} \mathrm{C}$. and at $12^{\circ} \mathrm{C}$.

Adsorption at $37^{\circ} \mathrm{C}$. The great rapidity with which opsonin is adsorbed by a bacillary emulsion, makes accurate technique difficult. In this experiment the following mixture was prepared, the various constituents having, before mixing, been raised to the temperature of the incubator $\left(47^{\circ} \mathrm{C}\right.$. $)$ :

$0 \cdot 4$ c.c. end-piece $+0 \cdot 2$ c.c. saline $+0 \cdot 1$ bacillary emulsion.

After admixture the tube was placed in the shaker working in the incubator at $37^{\circ} \mathrm{C}$. Small samples were removed from the tube at various periods after mixing and immediately centrifugalised. No attempt was made, however, to maintain a temperature of $37^{\circ} \mathrm{C}$. during the centrifugalisation process. After ten minutes in the centrifuge the clear supernatant fluids were pipetted off. The phagocytic indices of these were estimated and compared with that of the unadsorbed serum.

Apparently, therefore, no less than $80 \%$ of the opsonin was removed practically during the short period required for thorough admixture of the bacilli with the serum. In ten minutes after admixture, a little over $90 \%$ was removed but no further depletion took place although 
samples were tested up to $2 \frac{1}{2}$ hours after admixture. Equilibrium between the bound and free opsonin was reached in 10 minutes (approximately).

Result :

(Period in centrifuge not counted)

Before adsorption

$1 \frac{1}{2}$ mins. after mixing

$5 \frac{1}{2} \quad,, \quad,, \quad$.

$9 \frac{1}{2} \quad, \quad, \quad$,

$18 \frac{1}{4},, \quad,$,

$31 \frac{3}{4} \quad, \quad, \quad$,

$49 \frac{1}{2} \quad,, \quad,$,

$57 \frac{1}{4},, \quad$,

$144 \quad,, \quad$, ,

$159 \frac{1}{2} \quad,, \quad$,

\begin{tabular}{|c|c|}
\hline Phagocytic Index & Percentage Adsorbed \\
\hline $11 \cdot 26=\frac{1149}{102}$ & -- \\
\hline $2 \cdot 30=\frac{470}{204}$ & $79 \cdot 5$ \\
\hline $1 \cdot 53=\frac{314}{204}$ & $86 \cdot 4$ \\
\hline $0.98=\frac{201}{204}$ & $91 \cdot 2$ \\
\hline $0 \cdot 86=\frac{130}{151}$ & $92 \cdot 3$ \\
\hline $1 \cdot 37=\frac{234}{170}$ & $87 \cdot 8$ \\
\hline $1 \cdot 28=\frac{175}{136}$ & $88 \cdot 6$ \\
\hline $1 \cdot 27=\frac{174}{136}$ & $88 \cdot 7$ \\
\hline $1 \cdot 01=\frac{207}{204}$ & $91 \cdot 0$ \\
\hline $0 \cdot 93=\frac{165}{176}$ & $91 \cdot 7$ \\
\hline
\end{tabular}

Adsorption at $12^{\circ} \mathrm{C}$. Technique similar to that employed in previous experiment. (See Chart XVI.)

Result :

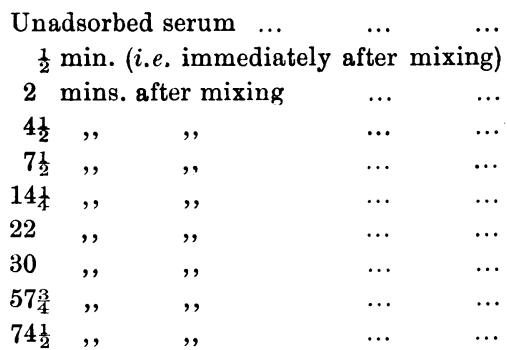

$\begin{array}{cc}\begin{array}{c}\text { Phagocytic } \\ \text { Index }\end{array} & \begin{array}{c}\text { Percentage } \\ \text { removed }\end{array} \\ 6 \cdot 28 & - \\ 2 \cdot 3 & 63 \cdot 3 \\ 1 \cdot 0 & 80 \cdot 8 \\ 0 \cdot 57 & 90 \cdot 9 \\ 0 \cdot 36 & 94 \cdot 2 \\ 0 \cdot 31 & 95 \cdot 0 \\ 0 \cdot 38 & 93 \cdot 9 \\ 0 \cdot 17 & 97 \cdot 2 \\ 0 \cdot 19 & 96 \cdot 9 \\ 0 \cdot 027 & 99 \cdot 5\end{array}$

As at $37^{\circ} \mathrm{C}$. so at $12^{\circ} \mathrm{C}$. adsorption took place with great rapidity, over $90 \%$ of the opsonin being removed in the first ten minutes. Further depletion occurred, however, at this temperature until no less than $99.5 \%$ was adsorbed. The fact that at $37^{\circ} \mathrm{C}$. equilibrium was reached at a very early stage, suggested that possibly under the influence 
of heat some dissociation of the adsorbed opsonin took place. The complete investigation of this question has not yet been attacked but it may be of interest to record the following experiment in which an attempt was made to demonstrate such dissociation as might occur.

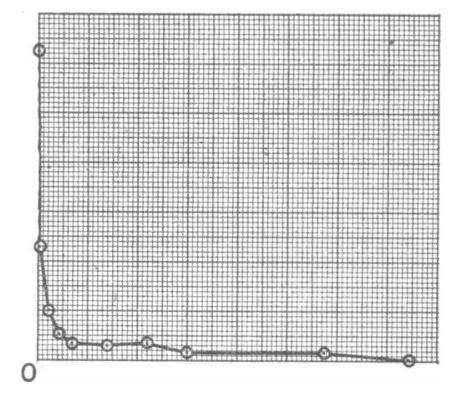

Chart XVI. Velocity of Adsorption. $x$. Time in minutes.

$y$. Phagocytic indices of supernatants.

\section{Technique.}

Three series of tubes were put up, each containing the same elements, viz.: 3 vols. end-piece +1 vol. saline +1 vol. bacillary emulsion.

\section{Series $A$.}

1. Immediately after mixing, the total volume was centrifugalised and the supernatant fluid collected.

2. Five minutes after mixing, the total volume was centrifugalised and the supernatant fluid collected.

3. Thirty minutes after mixing, the total volume was centrifugalised and the supernatant fluid collected.

As control the phagocytic index of the unadsorbed fluid was taken.

Series B.

1. Immediately after mixing, the total volume was centrifugalised. The clear supernatant fluid was then heated for 30 mins. at $56^{\circ} \mathrm{C}$.

2. Five minutes after mixing, the total volume was centrifugalised and the supernatant fluid similarly treated.

3. Thirty minutes after mixing, the total volume was centrifugalised and the supernatant fluid similarly treated.

As control to this series, the phagocytic index of the heated but unadsorbed serum was taken. 


\section{Series $C$.}

1. Immediately after mixing, the total volume was heated for 30 mins. at $56^{\circ} \mathrm{C}$. and finally centrifugalised.

2. Five minutes after mixing, a similar procedure was carried out.

3. Thirty minutes after mixing, a similar procedure was carried out. The control in this series was the same as that in Series B.

All the supernatant fluids in the three series were tested at the same time with the same fresh emulsion of B. typhosus.

Results : (see Chart XVII).

Unadsorbed fluid

Immediately after mixing

5 mins. after mixing

30 mins. after mixing

Series A
P. I.
$12 \cdot 6$
$3 \cdot 4$
$1 \cdot 3$
$0 \cdot 65$

Series C
P.I.
9.0
1.8
1.08
0.83

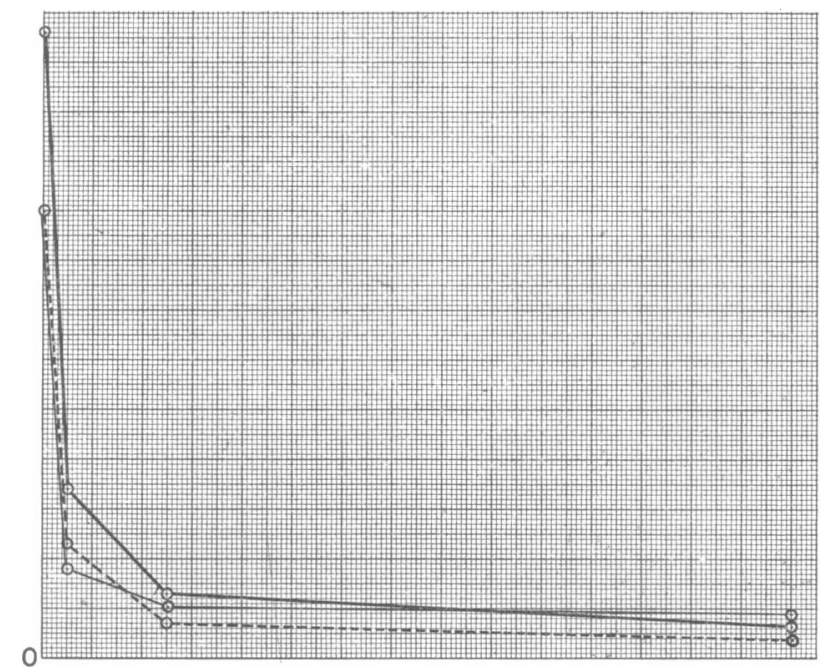

Chart XVII. Series A. Series B. Series C.

The series in which the supernatants were heated after centrifugalisation (Series B) show throughout slightly lower indices than Series A.

In Series $\mathrm{C}$ however (in which signs of dissociation were looked for) the indices after 5 mins. and 30 mins. are both appreciably higher than the corresponding indices in Series B which constitutes the proper 
control to Series C. The final index in Series $\mathrm{C}$ is, in fact, higher than the corresponding index in Series A in which no heat was applied either before or after centrifugalisation. I do not propose, however, to lay any stress on this result, as little more than a suggestion of dissociation of adsorbed opsonin by heat is indicated. The question will be again attacked by other methods.

\section{STAGE III.}

The phagocytosis of sensitised organisms suspended in salt solution.

In the experiments recorded in Stage II we have discussed the numerical relation subsisting between "bound" and "free " opsonin and we have shown that in equilibrium that relation can be expressed most accurately by an equation of the type characteristic of adsorption processes, viz., $\frac{y}{a}=K x^{n}$, where " $y$ " represents the amount of opsonin "bound," " $x$ " the amount of "free" opsonin when equilibrium has been reached, " $a$ " the concentration of bacilli employed for digestion and $K$ and $n$ are constants. The values of the exponent " $n$ " in three carefully conducted experiments of this type have been respectively $0.158,0.217$ and 0.48. The same sensitising fluid (end-piece) was used throughout.

I now proceed to describe the technique employed in the experiments of Stage III which were devised with the object of determining by numerical methods whether the actual phagocytosis of sensitised bacilli removed from the serum used for sensitisation and resuspended in saline, could be explained as an adsorption phenomenon.

Several difficulties had to be contended with before a satisfactory technique could be evolved, but the main difficulty lay in the choice of an appropriate concentration of bacilli for the preliminary sensitisation process. In the earlier orientating experiments some of which will be recorded, the concentration of bacilli used for adsorption was much too great for the available opsonin. Consequently when these bacilli were freed from serum, suspended in saline and presented in various concentrations to the leucocytes, very low phagocytic indices were obtained. Under such conditions it was also observed that the leucocytes themselves underwent considerable lytic changes probably owing to the leucotoxic action of unneutralised bacterial extract. In some experiments (not recorded here) it was ascertained that leucocytes in the presence of saline extracts of partially sensitised bacilli frequently showed degenerative changes whereas during a similar period in the presence of saline only 
or a heated saline extract of partially sensitised bacilli, no obvious lytic changes were detected. Under this heading no difficulty was experienced when as in the later experiments emulsions in saline of fully sensitised bacilli were employed.

\section{Experiment 1. (Preliminary.)}

One c.c. of end-piece was digested for 30 mins. at $37^{\circ} \mathrm{C}$ with $0 \cdot 2$ c.c. of a thick emulsion of B. typhosus. The supernatant fluid after centrifugalisation was removed, and the deposit of bacilli was washed twice with saline and again resuspended. Various dilutions of these bacilli in saline were then prepared.

Scheme of phagocytosis experiment :

1 vol. leucocytes +1 vol. of bacillary emulsion.

Result:

$\begin{array}{ccc}\text { Concentration of Bacilli } & \text { Phagocytic Index } \\ 1 \text { in } \quad 1 & 7 \cdot 2=\frac{590}{81} \\ 1 \text { in } & 2 & 0 \cdot 7=\frac{59}{83} \\ 1 \text { in } \quad 4 & 0 \cdot 6=\frac{81}{127} \\ 1 \text { in } & 8 & 0 \cdot 5=\frac{93}{185} \\ 1 \text { in } 16 & 0 \cdot 4=\frac{52}{117} \\ 1 \text { in } 32 & 0 \cdot 07=\frac{12}{170} \\ 1 \text { in } & 64 & ? \\ 1 \text { in } 128 & 0 \cdot 07=\frac{12}{168} \\ 1 \text { in } 256 & 0 \cdot 06=\frac{23}{337}\end{array}$

A gradual rise in the phagocytic index as the concentration of bacilli increased is apparent, but the very low intake per leucocyte (except in the case of the top figure) suggested that the bacilli had been very incompletely sensitised.

\section{Experiment II. (Preliminary.)}

0.4 c.c. end-piece was digested for 50 mins. at $37^{\circ} \mathrm{C}$. with $0 \cdot 1$ c.c. of a thick emulsion of bacilli.

Further technique as in Experiment I. 
Result :

$\begin{array}{ccc}\text { Concentration of Bacilli } & \text { Phagocytic Index } \\ 1 \text { in } 1 & 1 \cdot 18=\frac{242}{204} \\ 1 \text { in } \quad 2 & 1 \cdot 02=\frac{210}{204} \\ 1 \text { in } \quad 4 & 0 \cdot 42=\frac{86}{204} \\ 1 \text { in } \quad 8 & 0 \cdot 40=\frac{77}{190} \\ 1 \text { in } 16 & 0 \cdot 26=\frac{54}{204} \\ 1 \text { in } 32 & 0 \cdot 064=\frac{23}{359} \\ 1 \text { in } 64 & 0 \cdot 029=\frac{10}{343} \\ 1 \text { in } 128 & 0 \cdot 011=\frac{4}{345} \\ 1 \text { in } 256 & 0.012=\frac{5}{402} \\ 1 \text { in } 512 & 0.024=\frac{8}{322}\end{array}$

The indices are again low but there is a progressive increase in the intake per leucocyte as the concentration of bacilli increases.

\section{Experiment $I I I$.}

In this and later experiments, thin emulsions of B. typhosus were employed in the preliminary sensitisation process. By this means, a range of readily enumerable indices was obtained. Owing, however, to the resulting small deposit of sensitised bacilli, the range of indices was considerably shortened. In order therefore, to extend the range in the direction of the higher indices, recourse was had in some cases to the expedient of halving or quartering the leucocyte-concentration. In other cases, to attain the same object, several lots of bacilli were sensitised separately and the resulting deposits added together. It was then possible to obtain a satisfactory range of bacillary concentrations which would yield a satisfactory range of indices.

In Exp. III two lots of the following mixture were separately prepared and digested together for 20 mins.:

6 vols. end-piece +2 vols. saline +2 vols. thin emulsion of $B$. typhosus. The deposits were added together and washed twice in saline. Thereafter, various concentrations were put up. 
Result :

$\begin{array}{cc}\text { Concentration of Bacilli } & \begin{array}{r}\text { Phagocytic Index } \\ 4^{*}\end{array} \\ 18 \cdot 25 & =\frac{1479}{81} \\ 2^{*} & 22 \cdot 42=\frac{1166}{52} \\ 1 \text { in } 1 & 14 \cdot 92=\frac{3552}{238} \\ 1 \text { in } 2 & 8 \cdot 53=\frac{1092}{128} \\ 1 \text { in } 4 & 5 \cdot 33=\frac{544}{102} \\ 1 \text { in } 8 & 2 \cdot 70=\frac{276}{102} \\ 1 \text { in } 16 & 2 \cdot 01=\frac{274}{136} \\ 1 \text { in } 32 & 0 \cdot 65=\frac{67}{102}\end{array}$

* Obtained by dilution of the leucocytes.

\section{Experiment IV.}

The following mixture was digested for 10 mins.

6 vols. end-piece +2 vols. saline +3 vols. bacillary emulsion.

The deposit of bacilli, after washing, was concentrated by reducing the volume of saline from 11 to 3 . Various concentrations were then put up.

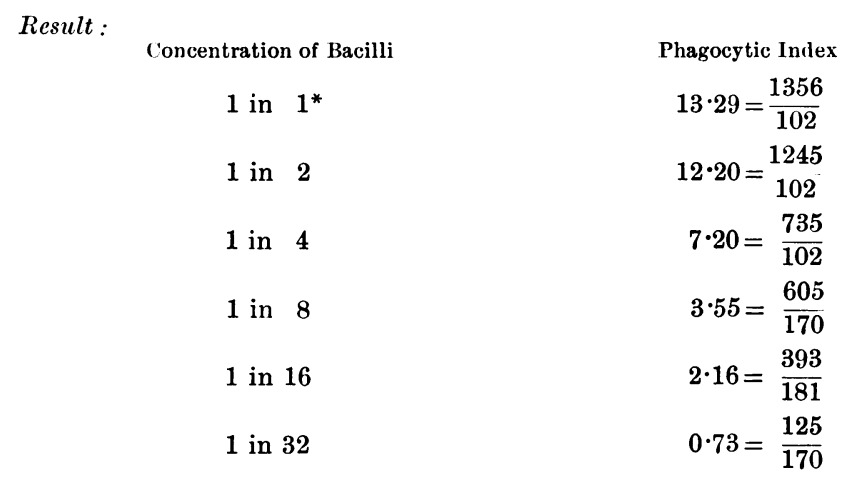

* Obtained by dilution of the leucocytes.

The results of Exps. III and IV have not been submitted to mathematical analysis as the ratio $B / L$ was not calculated and consequently the amount of bacilli "free" (i.e. not phagocytosed) could not be ascertained. In the following experiments this initial ratio was calculated. 


\section{Experiment $V$.}

Result :

$\begin{array}{cccc}\text { B/L } & \begin{array}{c}\text { P. I. or } \\ \text { Bacilli "Bound" }\end{array} & \begin{array}{c}\text { Bacilli "Free" } \\ \text { (i.e. B/L - P. I. })\end{array} & \begin{array}{c}\text { Percentage of } \\ \text { Bacilli "Bound " }\end{array} \\ 114 & 27 \cdot 09 & 86 \cdot 91 & 23 \cdot 76 \\ 57 & 21 \cdot 18 & 35 \cdot 82 & 37 \cdot 33 \\ 28 \cdot 5 & 11 \cdot 75 & 16 \cdot 75 & 41 \cdot 22 \\ 14 \cdot 25 & 7 \cdot 23 & 7 \cdot 02 & 50 \cdot 73 \\ 7 \cdot 125 & 3 \cdot 74 & 3 \cdot 385 & 52 \cdot 49 \\ 3 \cdot 562 & 1 \cdot 84 & 1 \cdot 722 & 51 \cdot 64 \\ 1 \cdot 781 & 1 \cdot 22 & 0 \cdot 561 & 68 \cdot 49 \\ 0 \cdot 890 & 0 \cdot 84 & 0 \cdot 0506 & 94 \cdot 31 \\ 0 \cdot 445 & 0 \cdot 36 & 0 \cdot 0853 & 80 \cdot 84\end{array}$

It will be seen that as the concentration of bacilli (and consequently the ratio $\mathrm{B} / \mathrm{L}$ ) diminishes, the percentage of "bound " or phagocytosed bacilli slowly but progressively increases.

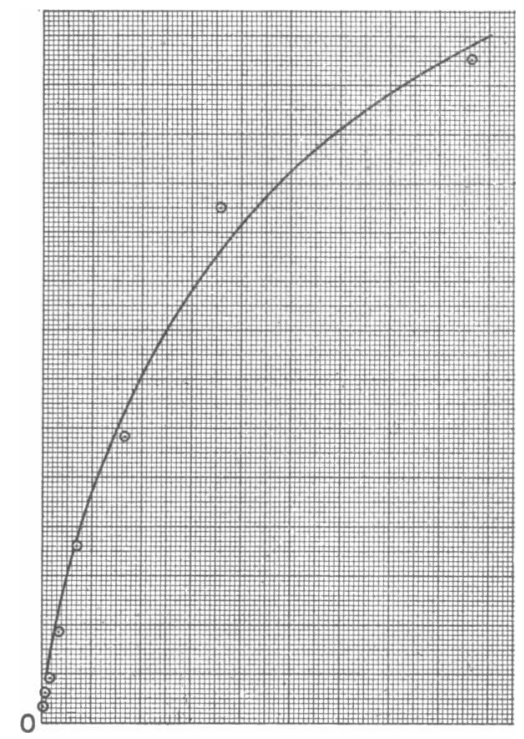

Chart XVIII. $x$. Bacilli "free." $y$. Bacilli "bound."

In Chart XVIII the bacilli "bound" (ordinates) have been plotted against the bacilli "free" (as abscissae), and in Chart XIX the logarithms of these quantities have been plotted. With the exception of the 8th which is badly out, all these points lie very closely on either side of a straight line. By the method of moments (omitting the 8th point) the 
value of 0.655 has been calculated for the exponent " $n$." This value yields the following figures for $\log K^{1}$ :

$\begin{array}{cr}0 \cdot 852 & \text { and for } K^{1} 7 \cdot 12 \\ 0.997 & 9 \cdot 95 \\ 0.958 & 9 \cdot 08 \\ 0.994 & 9 \cdot 87 \\ 0.916 & 8 \cdot 24 \\ 0 \cdot 800 & 6 \cdot 31 \\ 0.940 & 8 \cdot 72 \\ ? & ? \\ 0.947 & 8 \cdot 85\end{array}$

Considering the technical difficulties of the method, these figures must be regarded as highly satisfactory.

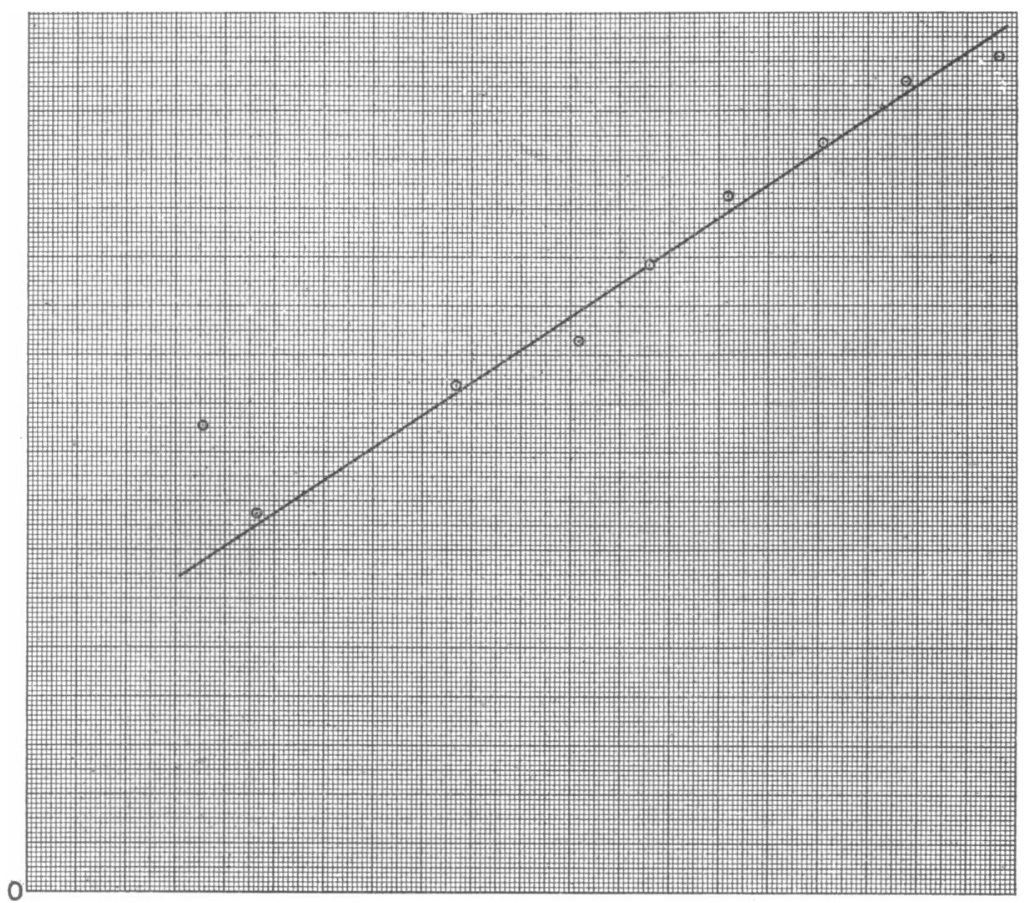

Chart XIX. x. Log. Bacilli "free." $y$. Log. Bacilli " bound."

\section{Experiment VI.}

Three lots of the following mixture were digested and the deposits collected and washed:

3 vols. end-piece +1 vol. saline +1 vol. bacillary emulsion.

The leucocyte and bacillary emulsions were counted so that the ratio of $\mathrm{B} / \mathrm{L}$ in the various mixtures was calculated. 
The rise in the percentage of bacilli "bound" as the initial concentration diminishes, is again very slow and gradual and the highest percentage reached is only $34.68 \%$.

The fall in the case of the two latter percentages is somewhat difficult to explain. It is most probably due to experimental error in estimating the final low indices.

$\begin{array}{cccc}\text { Result: } & \begin{array}{c}\text { P. I. or } \\ \text { Bacilli "Bound" }\end{array} & \begin{array}{c}\text { Bacilli “Free" } \\ (\text { i e. B/L - P. I. })\end{array} & \begin{array}{c}\text { Percentage of } \\ \text { Bacilli "Bound" }\end{array} \\ \text { B/L } & 29 \cdot 22 & 506 \cdot 78 & 5 \cdot 4 \\ 536 & 17 \cdot 35 & 250 \cdot 65 & 6 \cdot 4 \\ 268 & 16 \cdot 20 & 117 \cdot 8 & 12 \cdot 08 \\ 134 & 9 \cdot 47 & 57 \cdot 53 & 14 \cdot 13 \\ 67 & 5 \cdot 86 & 27 \cdot 64 & 17 \cdot 49 \\ 33 \cdot 5 & 4 \cdot 02 & 12 \cdot 73 & 24 \cdot 00 \\ 16 \cdot 75 & 2 \cdot 19 & 6 \cdot 18 & 26 \cdot 16 \\ 8 \cdot 375 & 1 \cdot 45 & 2 \cdot 73 & 34 \cdot 68 \\ 4 \cdot 187 & 0 \cdot 46 & 1 \cdot 63 & 22 \cdot 0 \\ 2 \cdot 09 & 0 \cdot 18 & 0 \cdot 86 & 17 \cdot 22 \\ 1.04 & & & \end{array}$

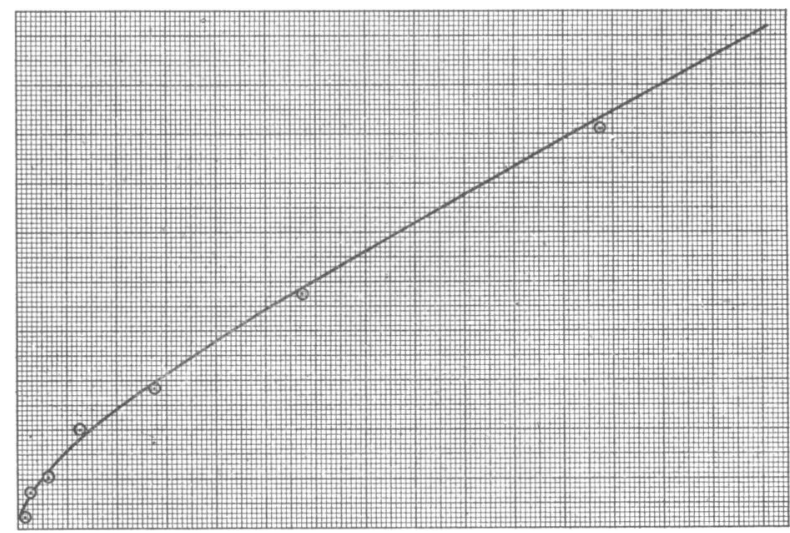

Chart XX. x. Bacilli "free." $y$. Bacilli "bound."

\section{Analysis.}

In Chart XX the "bound" bacilli are plotted as ordinates and the "free" bacilli as abscissae. In Chart XXI are plotted the points corresponding to the logarithms of these quantities. These points (with the exception of the 9 th and 10th) are seen to lie closely on either side of a straight line. 
By the method previously explained (omitting the two final points) a value of " $n$," viz. 05577 , was calculated which yielded the following values for $\log K^{1}$ :

$\begin{array}{rr}0 \cdot 354 & \text { and for } K^{1} \cdot 2 \cdot 26 \\ 0 \cdot 301 & 2 \cdot 00 \\ 0 \cdot 464 & 2 \cdot 91 \\ 0 \cdot 403 & 2 \cdot 52 \\ 0 \cdot 376 & 2 \cdot 37 \\ 0 \cdot 404 & 2 \cdot 53 \\ 0 \cdot 319 & 2 \cdot 08 \\ 0 \cdot 342 & 2 \cdot 19\end{array}$

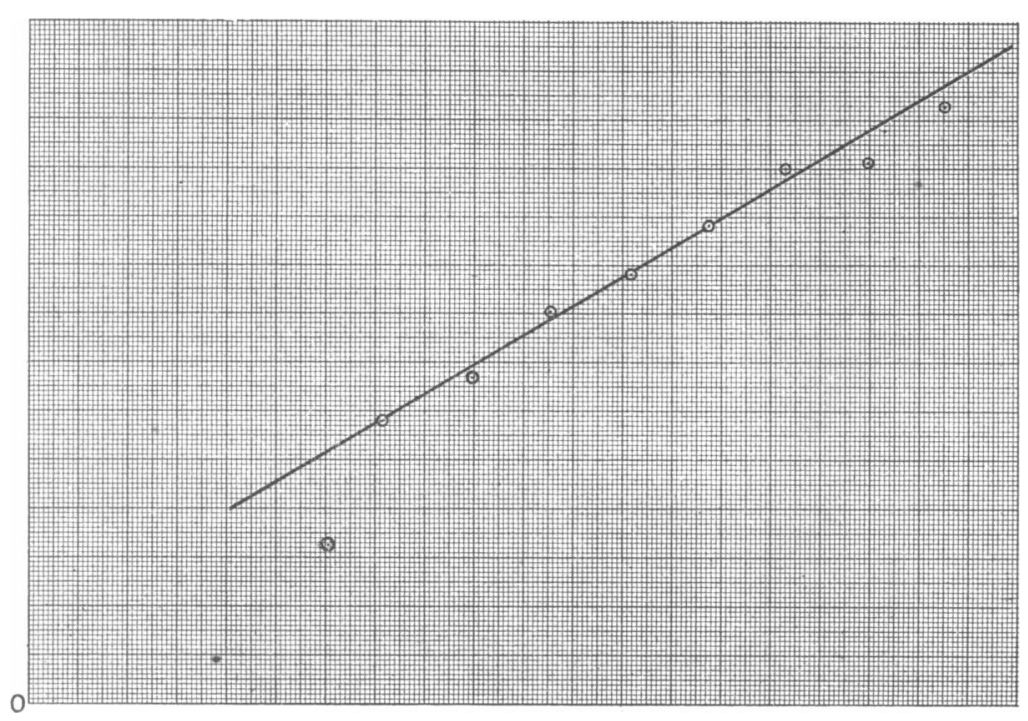

Chart XXI. $x$. Log. Bacilli "free." y. Log. Bacilli " bound."

In Chart XXII are plotted the amounts of bacilli "bound" as ordinates and of bacilli "free" as abscissae. In the same chart the logarithms of these amounts are plotted against each other. It is seen at a glance, that with the exception of the 7 th all these points lie on a straight line.

Also a mere inspection of the figures for the phagocytic indices shows, that as the initial bacillary concentration is doubled, the phagocytic index is also very nearly doubled. Consequently the percentage of the bacilli "bound" remains almost constant. In reality, however, the percentages lie within a very short range from $22 \cdot 8 \%$ to $30.3 \%$. The value of the exponent " $n$ " is thus very nearly unity.

Journ. of Hyg. xII 


\section{Experiment VII.}

Scheme: 6 vols. end-piece +2 vols. saline +2 vols. of thin bacillary emulsion digested together for 15 mins. at $12^{\circ} \mathrm{C}$.

Deposit washed, resuspended in saline, and various concentrations prepared therefrom.

Result :

$\begin{array}{lccc}\text { B/L } & \begin{array}{c}\text { P. I. or } \\ \text { Bacilli "Bound" }\end{array} & \begin{array}{c}\text { Bacilli “Free" } \\ (\text { i.e. B/L-P. I. })\end{array} & \begin{array}{c}\text { Percentage of } \\ \text { Bacilli "Bound " }\end{array} \\ 59 & 13 \cdot 5 & 45 \cdot 5 & 22 \cdot 8 \\ 29 \cdot 5 & 7 \cdot 93 & 21 \cdot 57 & 26 \cdot 8 \\ 14 \cdot 75 & 4 \cdot 10 & 10 \cdot 65 & 27 \cdot 7 \\ 7 \cdot 37 & 2 \cdot 03 & 5 \cdot 345 & 27 \cdot 5 \\ 3 \cdot 687 & 1 \cdot 12 & 2 \cdot 567 & 30 \cdot 3 \\ 1 \cdot 843 & 0 \cdot 517 & 1 \cdot 326 & 28 \cdot 0 \\ 0 \cdot 921 & 0 \cdot 168 & 0 \cdot 753 & 18 \cdot 2\end{array}$

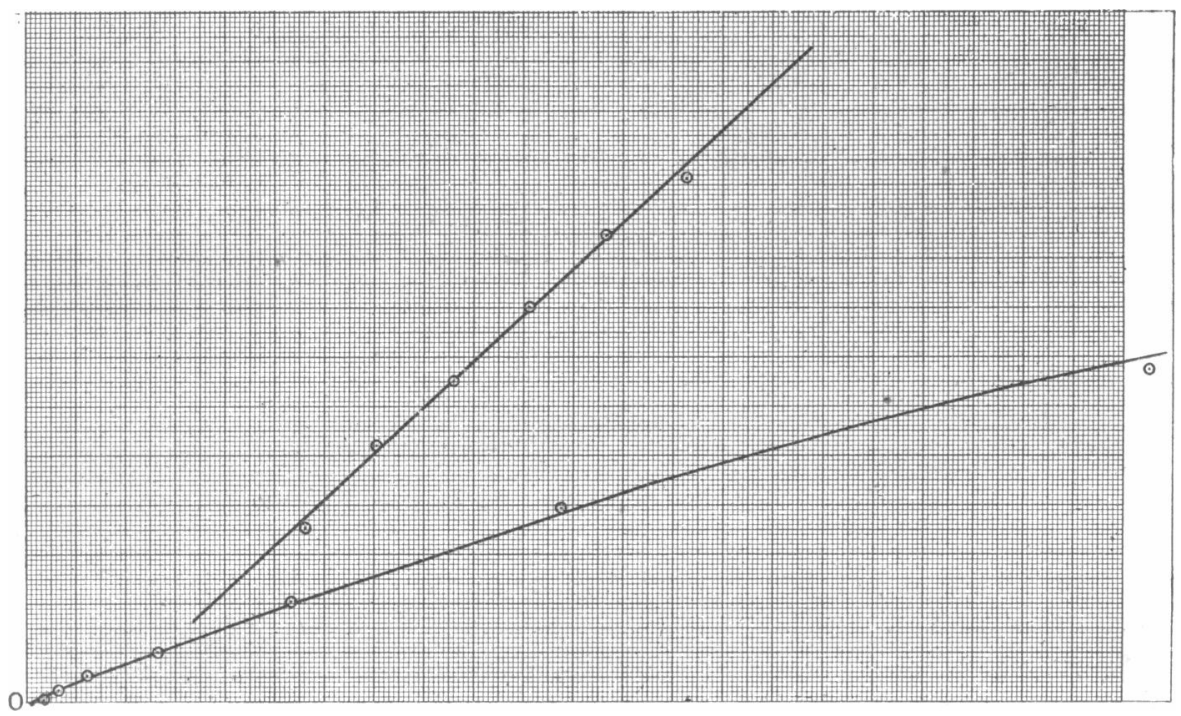

Chart XXII. x. Log. Bacilli "free." y. Log. Bacilli "bound." (Upper curve.) $x$. Bacilli "free." $y$. Bacilli " bound." (Lower curve.)

By the usual method of calculation the value 0.92 for " $n$ " gives the inclination of a straight line which passes most closely through the experimental points. The equation to this line which is drawn on the chart is $y=0.92 x-0.277$. 


\section{General remarks on Experiments V, VI and VII.}

In these three experiments we have endeavoured to ascertain by actual numerical methods whether the inclusion by leucocytes of sensitised bacilli suspended in a neutral fluid could be explained on an adsorption basis and we have shown that with due regard to difficulties of technique, the relation between the amounts of bacilli taken up by the leucocytes and the amounts left free in the surrounding fluid can be expressed most satisfactorily by an equation of the form $y=K x^{n}$. The values obtained for " $n$ " in these experiments, viz. $0.655,0.577$ and 0.92 are considerably higher than those calculated in the experiments of Stage II where the actual adsorption of opsonin by bacilli was discussed.

A further series of experiments similar to those of Stage III was contemplated but owing to exhaustion of the special sensitising fluid (guinea-pig end-piece) employed throughout the work, these experiments could not be carried out. It is proposed, however, to continue the investigation of this subject by aid of an end-piece derived from an immune antiserum obtained by immunisation of the rabbit with $B$. typhosus and the results recorded in the present communication though forming in themselves a fairly complete whole, are to be regarded in the light of a preliminary contribution to the subject.

\section{Summary and Conclusions.}

The two processes involved in the phagocytosis of bacilli (B.typhosus) by polymorphonuclear leucocytes in the presence of a sensitising fluid, viz. (1) the sensitisation of the micro-organism, and (2) the phagocytosis of the sensitised micro-organism, have been separately investigated. A single guinea-pig end-piece acted as the sensitising fluid throughout all the experiments.

The removal of opsonin by bacillary emulsions was found to run the course of an adsorption process as evidenced by the numerical relations found to subsist between the bound and free opsonin in equilibrium.

Also the actual phagocytosis of sensitised or partially sensitised micro-organisms suspended in a neutral fluid (physiological saline) was found, on analysis by similar numerical methods, to proceed as an adsorption process. 


\section{REFERENCES.}

Barikine (1911). Sur le mécanisme de la phagocytose in vitro. Zeitschr. fuir Immunitätsf., Orig. viII. 72.

Ledingham (1908). The Influence of temperature on Phagocytosis. Proc. Roy. Soc., Ser. B. Lxxx. 188.

Levaditi and Mutermilch (1910). Mécanisme de la phagocytose. Compt. rend. de la Soc. de Biol., I. 1079.

RhUmbler (1910). Die verschiedenartigen Nahrungsaufnahmen bei Amöben als Folge verschiedener Colloidalzustände ihrer Oberflächen. Archiv für Entwickelungsmechanik der Organismen, xxx. 194.

Ullmann (1911). Ueber physiologische und Reiz-Bewegungserscheinungen an Leukocyten. Virchow's Archiv, cCv. 303. 